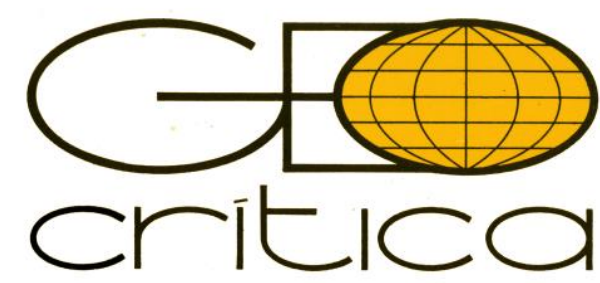

\title{
LA PANDEMIA Y EL GEOFORO IBEROAMERICANO EN 2020
}

\author{
Benito Campo País \\ Universitat de València \\ Benito.Campo@uv.es \\ Sara Fita Esteve \\ IES Eduardo Primo Marqués, Carlet \\ sara.fita.86@gmail.com \\ María Martínez Camarena \\ IES Font de Sant Lluís, València \\ martinez_mari@gva.es \\ Xosé Manuel Souto González \\ Universitat de Valencia \\ Xose.manuel.souto@uv.es
}

Grupo de investigación Socialsuv (Universidad de Valencia) y Proyecto educativo Gea-Clio.

\section{La pandemia y el Geoforo Iberoamericano en 2020 (Resumen)}

La pandemia de la COVID-19, que nos afecta desde los primeros meses de 2020, ha modificado nuestras costumbres y rutinas. Y también la manera de relacionarnos en los medios escolares y universitarios. Desde el Geoforo Iberoamericano sobre Educación, Geografía y Sociedad hemos considerado que se abría una oportunidad para re-pensar los problemas sociales y ambientales que condicionan nuestra cotidianidad. Desde el estudio de situaciones particulares hemos querido definir los problemas intelectuales que sean susceptibles de ser trabajados en las aulas. Esta consideración es fruto de la evolución que venimos manteniendo desde 2008 y que se valoró en el Coloquio de 2019 en Bogotá, del cual también damos cuenta en este artículo. Constancia y coherencia en una tarea de largo recorrido, para la que nos gustaría contar con aquellas personas que entienden que la educación escolar sirve para explicar los factores profundos y ocultos que determinan nuestro comportamiento en el espacio local y global.

Palabras clave: Geoforo; pandemia; problemas sociales; redes educativas; compromiso ciudadano. 


\section{A pandemia e o Geoforo Ibero-americano em 2020 (Resumo)}

A pandemia COVID-19, que nos afeta desde os primeiros meses de 2020, modificou os nossos costumes e rotinas. E também a forma como interagimos nos meios escolares e universitários. Desde o Geoforo Ibero-americano de Educação, Geografia e Sociedade consideramos que se abre uma oportunidade para repensar os problemas sociais e ambientais que condicionam o nosso quotidiano. A partir do estudo de situações específicos, desejamos definir os problemas intelectuais que, provavelmente, serão trabalhados em sala de aula. Esta reflexão é resultado da evolução que temos mantido desde 2008 e que foi valorizada no Colóquio 2019 em Bogotá, como relatamos neste artigo. Constância e coerência numa tarefa de longo prazo, para a qual gostaríamos de ter aquelas pessoas que entendessem que a educação escolar serve para explicar os fatores profundos e ocultos que determinam o nosso comportamento no espaço local e global.

Palavras-chave: Geoforo, pandemia, problemas sociais, redes educativas, compromisso cidadão.

\section{The Ibero-American pandemic and Geoforo in 2020 (Abstract)}

The pandemic of COVID-19, which concerns us since the first months in 2020, has changed our costumes and routines. Also, the way we are in contact with people in schools and universities. From the Geoforo Iberoamericano de Educación, Geografía y Sociedad have considered that it existed the opportunity to rethink the social and environmental problems which determine our everyday nature. From the research of particular situations, we would like to define the intellectual problems that are sensitive to be worked in the classrooms. This consideration results from the evolution which we are keeping up from 2008 and it was valued in the Colloquium in 2019 in Bogota, from whom we refer in this article. Perseverance and coherence in a long-term task, which we would like to count on those people who understand education as a tool to explain the deep and hidden factors which determine our behaviour in local and global spaces.

Key words: Geforo, pandemic, social problems, educational networks, citizen engagement.

\section{Introducción}

Desde 2010 hasta 2018 se han venido publicando los resúmenes anuales del Geoforo: Foro Iberoamericano sobre Educación, Geografía y Sociedad, que se había constituido en $2008^{1}$. En el año 2019, como consecuencia de la celebración del Primer Coloquio de Enseñanza de la Geografía y Ciencias Sociales, no se publica este balance anual, pues en el evento celebrado en Bogotá se dio cuenta de las visitas, opiniones registradas, noticias y documentos que se han archivado para consulta de estudios posteriores ${ }^{2}$.

El blog ubicado en la plataforma Geocrítica de la Universidad de Barcelona ${ }^{3}$ consta de ocho secciones y es accesible para cualquier persona interesada. Las secciones más relevantes son las que permiten la opinión de los lectores (Foro y Foro Extraordinario) que se conciben como lugares de encuentro y contraste de argumentos sobre los problemas seleccionados. En la sección de noticias se destacan algunas novedades que pueden ser relevantes para la educación; nunca más de dos noticias semanales. En Archivo del Foro se registran documentos ya editados

\footnotetext{
${ }^{1}$ El primer balance en Biblio3W se publica en 2010: Souto, X., Claudino, S. y García, F., 2010; recuperado de <http://www.ub.es/geocrit/b3w-902.htm>. El último publicado corresponde al año 2018: Fita, S., Claudino, S. y Souto, X., 2018, recuperado de <http://www.ub.es/geocrit/b3w-1258.htm>.

2 Ver Rodríguez, L.; Palacios, N. y Souto, X., 2019; así como el resumen realizado en Biblio3W $<$ https://revistes.ub.edu/index.php/b3w/article/view/28493>.

$3<$ http://geoforo.blogspot.com/>.
} 
en otras secciones, para que puedan ser consultados por los lectores. Finalmente, las secciones de recursos, enlaces, colabora y nosotros, permite a las personas que entran en el Geoforo poder conocer a las personas y recursos que se ofrecen a la comunidad educativa. Desde el verano de 2019 se ha abierto un segundo Geoforo en la UNAM de México, como se dirá, que analiza los debates que se van produciendo en los foros de la plataforma de Geocrítica.

En esta ocasión, por medio de la revista Aracne, queremos dar cuenta de los balances de los años 2019 y 2020, así como de las actuaciones que se han promovido en relación con la pandemia de la COVID-19, con énfasis en las transformaciones de las actividades educativas, en especial en el sistema escolar reglado.

La pandemia del virus SARS-2 nos ha modificado muchas costumbres diarias, en especial las referidas a la socialización informal, en momentos de ocio. Pero también ha afectado a las relaciones laborales y a la investigación académica. Se ha hecho evidente que el saber científico es un proceso inestable, que procede del conocimiento que se dispone en un momento dado y de la verosimilitud de los datos observados; además en este caso, cuando se refieren a acciones humanas, hemos visto que los datos numéricos pueden estar falseados y que no "hablan" si no le sabemos preguntar. Por eso, desde las primeras ediciones de los balances anuales del Geoforo, hemos insistido en combinar los datos de las visitas con las de las opiniones colocadas, analizando el contenido cualitativo de éstas.

Se hace así palmario que la metodología de las ciencias sociales se apoya en métodos cualitativos y cuantitativos, pues sin la complementariedad de ambos es imposible afrontar una explicación rigurosa de los hechos sociales, en este caso educativos. Una verdad que parece de Perogrullo, pero ha generado intensos debates, con implicaciones emocionales y racionales. Nosotros seguimos apostando por la misma metodología que complementa los métodos cuantitativos con los cualitativos.

La estructura de este artículo se compone de cuatro epígrafes básicos. En primer lugar, presentamos la estructura del Geoforo y abordamos la descripción de las visitas y opiniones que se han colocado en sus diversas secciones, como son los foros, noticias, archivos del foro o recursos. Más tarde, analizamos el contenido de dichas aportaciones, analizando su procedencia y el impacto que tiene en el aprendizaje del alumnado. A continuación, analizamos el caso concreto de la pandemia, donde las personas que colaboran en la divulgación de esta red de Geoforo, se han manifestado a favor de una serie de acciones que presupongan el análisis crítico de la información que recibimos en cantidades ingentes para poder ser procesada racionalmente. Finalmente, hacemos una valoración de los objetivos que nos hemos trazado desde 2008, con el propósito de adaptarlos a las nuevas expectativas del ámbito educativo, pero también con la necesidad de preservar el rigor de todo razonamiento empírico y contrastable.

\section{El Geoforo Iberoamericano en Internet: Estructura y estadísticas de uso}

Como se ha indicado en líneas precedentes, el Geoforo Iberoamericano consta de ocho secciones diferentes, que se organizan después de un proceso complejo, que supuso transferir la buena voluntad de crear una red escolar de conocimiento crítico hasta alcanzar un blog que respondiera a nuestras necesidades; deseábamos generar un diálogo constructivo sobre los problemas que observábamos en las tareas escolares, en sus diferentes niveles, que adoptan 
diferentes denominaciones en los países iberoamericanos ${ }^{4}$. La estructura del Geoforo es dinámica y responde a las necesidades de los participantes.

Por este motivo en los meses finales de 2019 abrimos la posibilidad de completar la participación escolar a través de una nueva web, alojada esta vez en la Universidad Nacional de México (UNAM) ${ }^{5}$. Si alojar en blog inicial en la plataforma Geocrítica de la Universidad de Barcelona estaba avalado por las finalidades compartidas respecto al papel del conocimiento crítico en el ámbito educativo, en este segundo caso se justificaba la apertura por la influencia que tiene la UNAM sobre el conjunto de universidades de América Latina y por la posibilidad de mantener de forma más estable una página web. Además, se ha configurado ésta de forma complementaria, pues se diseñaron un conjunto de hilos conceptuales para poder organizar la dispersión de argumentos que se colocaban por las personas participantes. Es decir, el incremento de las opiniones ha dado lugar a nuevas necesidades y desde la UNAM hemos dado respuesta a las mismas. La experiencia de estos meses nos indica que la participación se ha distribuido de acuerdo con los objetivos iniciales.

Para posibilitar la participación escolar en sus diferentes ámbitos y sujetos se había previsto dicha estructura con ocho secciones: una inicial que presenta las finalidades; a continuación, los Foros de debate para intercambiar opiniones y argumentos; dicha sección se ha desdoblado con una nueva: Foro Extraordinario, para recoger los matices y experiencias sobre los foros ya realizados. Luego la sección del Archivo del foro, en la cual pensábamos exponer debates sobre producciones académicas; después la sección de Noticias, con el objetivo de intercambiar asuntos locales desde una perspectiva global. También aparece la sección de Recursos con la finalidad de colocar listados bibliográficos y unidades didácticas; en la sección de Enlaces pretendíamos que cualquier lector pudiera acceder a las webs más relevantes de la didáctica de las ciencias sociales; en la sección Colabora se estimula a la participación. Finalmente, en Nosotros damos cuenta de las biografías de las personas que componen el consejo directivo del Geoforo Iberoamericano, Educación, Geografía y Sociedad.

La valoración anual realizada en los sucesivos balances anuales nos ha permitido conocer cuáles son los intereses de las personas que acuden a informarse y formarse en este blog. En este sentido podemos subrayar la importancia de los foros frente al resto de contenidos, lo que nos invita a valorar no tanto las visitas, sino sobre todo las contribuciones a través de opiniones y argumentos. Una tendencia que se ha mostrado a lo largo del último decenio, como se puede verificar en los balances anuales publicados.

Así, los datos numéricos de las visitas mensuales de los años 2019 y 2020 nos permiten visualizar el interés mostrado por los lectores de este blog en relación con la apertura de nuevos foros, o bien con el registro de síntesis y actualizaciones de documentación. En el año 2019 se puede apreciar la influencia del Coloquio de Bogotá ${ }^{6}$ y, sobre todo, la apertura del Foro 25 sobre el medio rural ${ }^{7}$, que generó un importante incremento de visitas en mayo de 2019. En el Coloquio de Bogotá se aprecia un aumento relevante del total de visitas a las Noticias, mientras que en el caso del Foro del medio rural su incidencia se destaca en la sección de foros. Es decir, hay una coherencia interna de los datos, pues preocupaban las noticias en relación con la

\footnotetext{
${ }^{4}$ Sobre los problemas de migración de los primeros años del Geoforo se puede consultar Souto y Durán, 2011

$<$ http://www.ub.edu/geocrit/b3w-955.htm>.

$5<$ http://www.geoforo.unam.mx/secforo/index.php>.

${ }^{6}<$ https://revistes.ub.edu/index.php/b3w/article/view/28493>.

7 <http://geoforoforo2.blogspot.com/2019/04/foro-25-el-medio-rural-en-la-educacion.html>.
} 
celebración del evento y, por otra parte, se entraba en los dos foros más recientes (los números 25 y $26^{8}$, éste sobre sobre la pandemia), para poder opinar.

Cuadro 1. Datos de las visitas por secciones/meses 2019

\begin{tabular}{|l|l|l|l|l|l|l|l|l|l|l|l|l|}
\hline & ENE. & FEB.. & MAR. & ABR. & MAY. & JUN. & JUL & AGO. & SEP. & OCT. & NOV. & DIC. \\
\hline Noticias & 490 & 235 & 445 & 303 & 249 & 222 & 890 & 281 & 304 & 598 & 558 & 245 \\
\hline Foro & 3422 & 2972 & 2328 & 2078 & 4261 & 3100 & 1099 & 1497 & 1548 & 2116 & 1763 & 1455 \\
\hline Nosotros & 41 & 34 & 76 & 73 & 72 & 64 & 64 & 41 & 44 & 29 & 32 & 22 \\
\hline Recursos & 41 & 29 & 45 & 39 & 56 & 49 & 58 & 65 & 25 & 49 & 55 & 36 \\
\hline Enlaces & 23 & 17 & 23 & 17 & 27 & 22 & 30 & 15 & 16 & 27 & 21 & 9 \\
\hline Archivo Foro & 313 & 161 & 317 & 232 & 208 & 173 & 234 & 400 & 113 & 158 & 188 & 105 \\
\hline Colabora & 29 & 27 & 33 & 23 & 46 & 21 & 33 & 16 & 26 & 30 & 28 & 21 \\
\hline Foro ext. & 69 & 49 & 120 & 117 & 177 & 77 & 106 & 90 & 75 & 122 & 84 & 90 \\
\hline Total & 4428 & 3524 & 3387 & 2882 & 5096 & 3728 & 2514 & 2405 & 2151 & 3129 & 2729 & 1983 \\
\hline
\end{tabular}

Fuente: Elaboración propia a partir de Google Analytics

Igualmente, en el año 2020 podemos apreciar la influencia de la apertura del Foro 26 sobre la pandemia, pues las visitas se incrementaron en los meses de marzo, abril y mayo. Además, se confirma que estas dos secciones, junto a la de Archivo del Foro ${ }^{9}$, son las más visitadas por las personas que desean obtener información sobre el Geoforo.

Por otra parte, en este balance anual hemos agregado el total las visitas registradas en el Foro $126^{10}$, que se ubica en la plataforma de la UNAM de México, tal como se ha señalado y que como vemos tuvo un mayor impacto en los meses de abril, mayo y junio. Tanto el Foro 26, como el 126 están relacionados con el Manifiesto publicado por el Consejo directivo y luego reproducido en varios lugares ${ }^{11}$, así como a un conjunto de tareas escolares que luego analizaremos. El Foro 26 responde a la necesidad de abrir un espacio para exponer los sentimientos, emociones y opiniones que surgen como consecuencia de la irrupción de la pandemia, mientras que el Foro 126 analiza y construye argumentos sobre las transformaciones que ha originado este evento en la vida cotidiana de las personas y países. Hay, pues, un intento de adaptarse a los problemas, más que construir un lugar institucional para visualizar una comunidad educativa.

Cuadro 2. Datos de las visitas por secciones/meses año 2020

\begin{tabular}{|l|l|l|l|l|l|l|l|l|l|l|l|}
\hline & ENE. & FEB. & MAR. & ABR. & MAY. & JUN. & JUL. & AGO. & SEP. & OCT. & NOV. \\
\hline Noticias & 141 & 236 & 529 & 590 & 760 & 223 & 175 & 209 & 212 & 233 & 233 \\
\hline Foro & 1640 & 3068 & 4.720 & 5808 & 4734 & 2693 & 1130 & 1140 & 1270 & 2072 & 2020 \\
\hline
\end{tabular}

\footnotetext{
$8<$ http://geoforoforo2.blogspot.com/2020/03/foro-26-el-coronavirus-una-experiencia.html>.

${ }^{9}<\mathrm{http}: / /$ geoforodocumentos.blogspot.com/>.

10 Ver foro 126 en la página web de la UNAM <http://www.geoforo.unam.mx/secforo/viewforum.php?f=25\&sid=6187f0149950c89fca1d13df64edf751>. ${ }^{11}<$ http://www.geoforo.unam.mx/secforo/viewforum.php?f=25\&sid=6187f0149950c89fca1d13df64edf751 www. socialsuv.org/manifiesto> y para las tareas <https://drive.google.com/drive/folders/1CjmuDDJj44CXmTbFNSOlfM7ZIGOIwtu?usp=sharing >. Igualmente en notas de prensa de la Universitat de València $<$ https://links.uv.es/XR2A8V7>, y en la revista Iber <https://www.grao.com/es/producto/revista-iber-101-octubre20-fake-news-y-pensamiento-critico-ib101> y en Diario Nuevo Siglo de Bogotá.
} 


\begin{tabular}{|l|l|l|l|l|l|l|l|l|l|l|l|}
\hline Nosotros & 20 & 40 & 53 & 43 & 55 & 42 & 37 & 30 & 23 & 31 & 63 \\
\hline Recursos & 35 & 37 & 67 & 69 & 117 & 72 & 80 & 72 & 94 & 92 & 119 \\
\hline Enlaces & 27 & 25 & 14 & 24 & 28 & 24 & 27 & 25 & 19 & 31 & 57 \\
\hline $\begin{array}{l}\text { Archivo } \\
\text { Foro }\end{array}$ & 68 & 137 & 484 & 471 & 656 & 339 & 173 & 142 & 77 & 119 & 143 \\
\hline Colabora & 10 & 22 & 19 & 20 & 30 & 19 & 22 & 28 & 19 & 37 & 57 \\
\hline Foro ext. & 46 & 133 & 103 & 471 & 126 & 59 & 73 & 343 & 111 & 130 & 100 \\
\hline $\begin{array}{l}\text { Foro 126 } \\
\text { UNAM }\end{array}$ & s.d. & s.d & 398 & 1022 & 1503 & 1235 & 55 & 85 & 18 & 191 & 202 \\
\hline Total & 1987 & 3698 & 6387 & 8518 & 8509 & 4706 & 1772 & 1974 & 1843 & 2854 & 2994 \\
\hline
\end{tabular}

Fuente: Elaboración propia a partir de Google Analytics

En consecuencia, la gráfica resultante (Figura 1) nos ofrece el incremento más acusado en la primera mitad del año, coincidiendo con la evolución del curso escolar en el hemisferio Norte. Los descensos de julio y agosto coinciden con la finalización del curso y la entrada en la época de las vacaciones estivales en el hemisferio boreal. Una apreciación gráfica que se complementa con los datos estadísticos que hemos ido registrando año tras año.

Cuadro 3. Número total de visitas (enero-noviembre) del Geoforo

\begin{tabular}{|l|l|l|l|l|l|l|}
\hline Años (hasta Nov) & 2015 & 2016 & 2017 & 2018 & 2019 & 2020 \\
\hline Visitas & 19677 & 20615 & 22820 & 20439 & 35973 & 45124 \\
\hline
\end{tabular}

Fuente: Elaboración propia a partir de Google Analytics

Para los once primeros meses de cada año podemos establecer una comparación de números absolutos, en la que podemos comprobar el aumento anual de visitas. Como se puede apreciar, el incremento es más notable a partir de 2019, cuando prácticamente se duplican las visitas registradas en años anteriores.

Figura 1. Evolución del número de visitas en las diferentes secciones del Geoforo

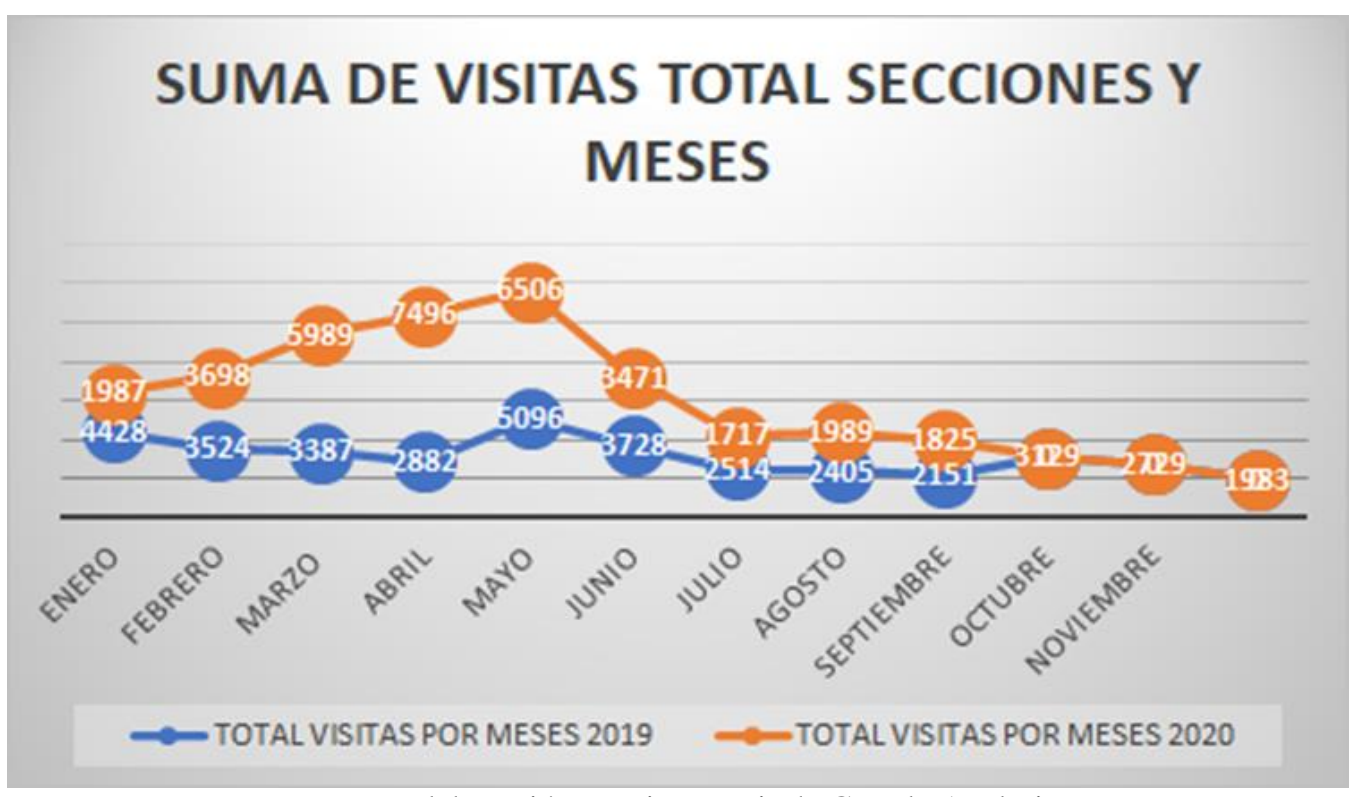

Fuente: Elaboración propia a partir de Google Analytics 
En consecuencia, apreciamos un importante crecimiento de las visitas respecto a los primeros años, como se puede comprobar en la figura 2, que indica que desde enero de 2011 ya se han registrado más de 140.000 visitas, en el blog ubicado en la plataforma Geocrítica ${ }^{12}$, y se habían colocado más de tres mil comentarios, lo que es mucho más significativo para los objetivos que nos habíamos propuesto.

Figura 2. Evolución de las visitas realizadas en el Geoforo desde 2011

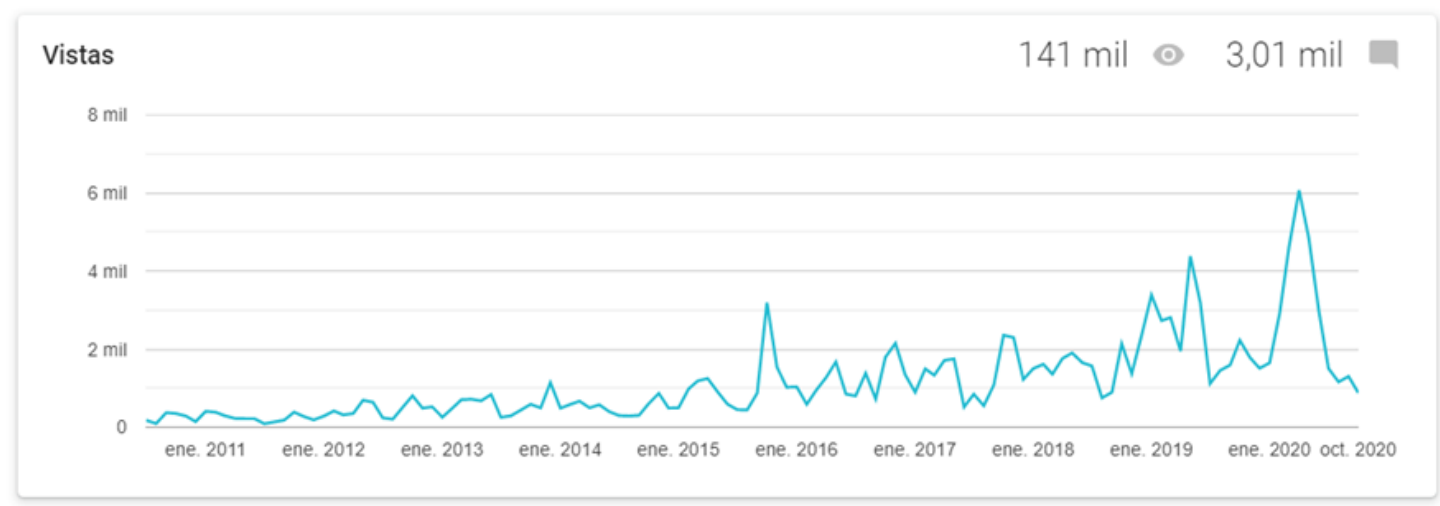

Fuente: Elaboración propia a partir de Google Analytics

Actualmente las herramientas informáticas nos permiten visualizar el comportamiento de cada foro, como después comprobaremos. Sin embargo, las visitas realizadas por países no son muy relevantes con el análisis de Google, pues al registrar el país de los servidores informáticos, no coincide en muchas ocasiones con el origen de la persona que visita el Geoforo. Como se puede apreciar en la figura 3, los datos de las visitas de Google nos remiten a países como Estados Unidos, Alemania, Reino Unido, Rusia, Nigeria o Australia que no participan de los debates.

Figura 3. Principales ubicaciones de las visitas del mes de octubre 2020 a la sección Foro

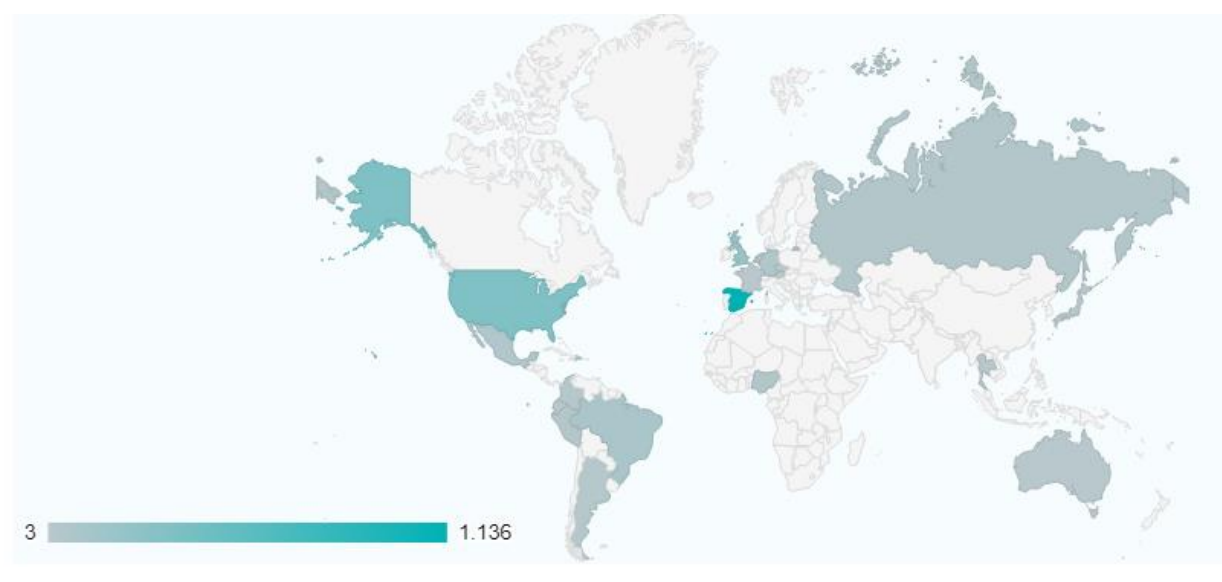

Fuente: Elaboración propia con Google Analytics ${ }^{13}$

Nuestra conjetura nos indica que numerosas visitas son automáticas desde ciertos servidores y con un afán de conocer qué información circula por la red. Más eficaz es el registro de la

\footnotetext{
$12<$ http://geoforo.blogspot.com/>.

${ }^{13}$ La elaboración de las figuras se realiza con datos de Google Anatlytics. a partir de Blogger, con contraseña de la webmaster.
} 
$\mathrm{UNAM}^{14}$, que nos muestra el origen del registro de la persona que quiere acceder al foro, además de los comentarios que realizan las personas que escriben sus opiniones en los foros (ver figura 4).

Figura 4. Países registrados en el nuevo Geoforo de la UNAM (México)

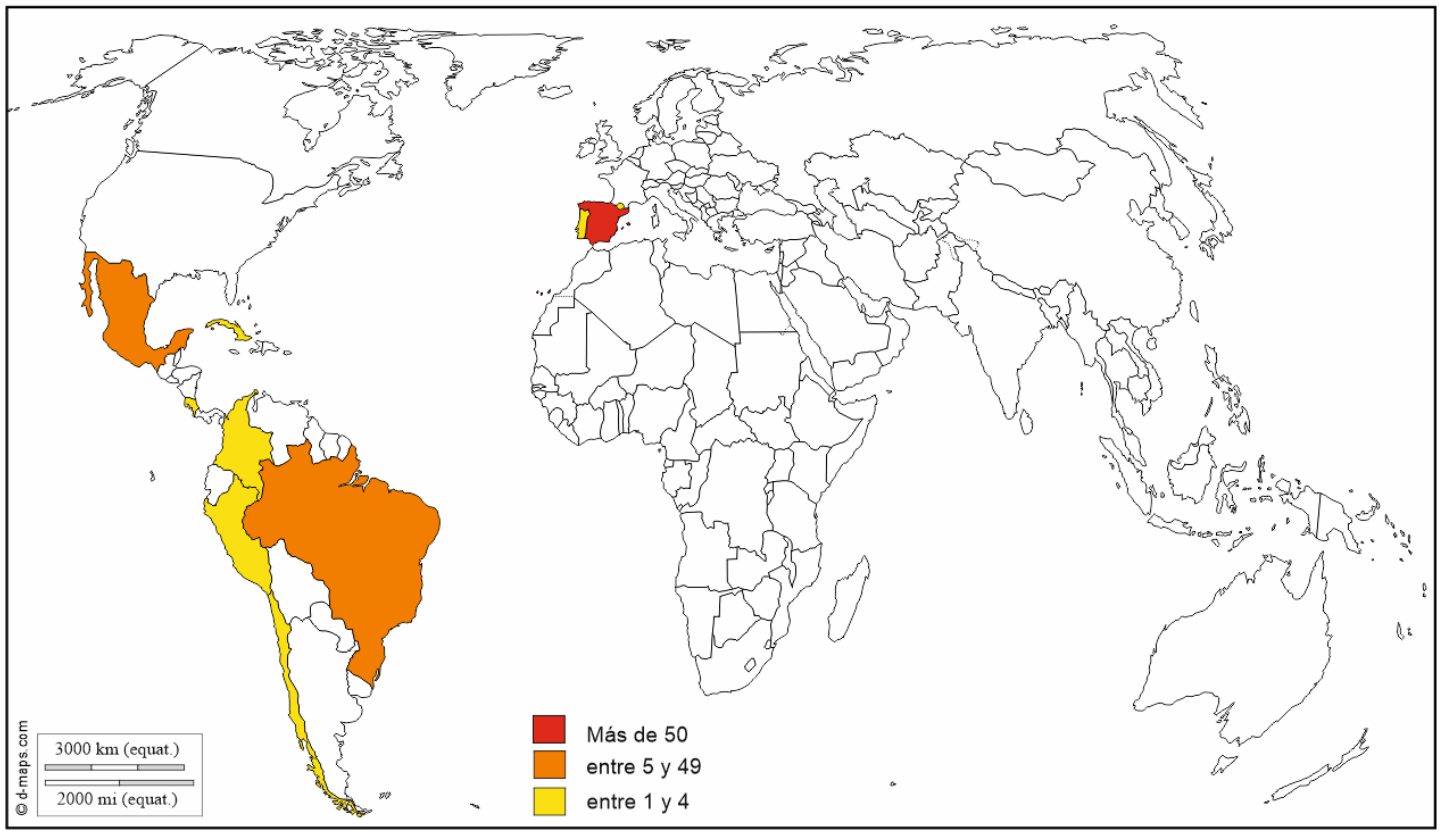

Fuente: Elaboración propia con datos del Geoforo-UNAM ${ }^{15}$

\section{El análisis de los contenidos del Geoforo}

El Geoforo se ha caracterizado por utilizar los instrumentos técnicos (blogs, webs, contadores analíticos) al servicio de sus finalidades, como hemos señalado en la introducción. La constitución de una red escolar que promueve el conocimiento crítico y la praxis didáctica es el objetivo principal. Por eso, no es lo más relevante para el Geoforo el número de visitas recibidas, sino el impacto en poder recoger e intercambiar opiniones y argumentos sobre los debates que se han propuesto. En este sentido, vamos a analizar cómo hay algunos foros que han merecido más interés por los lectores del Geoforo.

\section{Los Foros}

Como se puede comprobar en los últimos cinco años (cuadro 4), el Foro que ha despertado más interés es el de las salidas escolares, pese a que ya ha sido objeto de reseña ${ }^{16}$. Hasta finales de noviembre de 2020, se habían producido más de quinientas aportaciones de alumnos y alumnas universitarias, así como de sus docentes en la formación inicial. Tenemos constancia que su contenido forma parte del contenido formativo de la Universidade de São Paulo en el campus de Ribeirão Preto, con lo que se logra uno de los objetivos básicos del Geoforo, que es proyectar

\footnotetext{
${ }^{14}<$ http://www.geoforo.unam.mx/secforo/index.php?sid=6c312472c82991d98fe0b0d863b6a33f $>$. Se corresponde con el blog creado en la Universidad Autónoma de México (UNAM) y que alberga el nuevo Geoforo. Para poder opinar en este blog es preciso registrarse, de tal manera que es posible conocer el origen de las personas que participan en los debates.

${ }^{15}\langle$ http://www.geoforo.unam.mx/secforo/index.php?sid=6c312472c82991d98fe0b0d863b6a33f >.

${ }^{16}$ Ver Sousa, García y Souto, 2016 <http://www.ub.es/geocrit/b3w-1155.pdf>.
} 
el conocimiento colaborativo como parte esencial de la enseñanza de los problemas sociales. Los otros foros que suscitaron mayor interés fueron los referidos al proyecto Nós Propomos! $!^{17}$, tal como ya se comentó en el balance del año $2018^{18}$ y que supone la participación social y ciudadana del alumnado del sistema básico escolar en la resolución de los problemas locales. A continuación, aparece el foro relativo a los problemas de la pandemia, el Foro 26 (más de 450 opiniones en este primer año) y finalmente hemos de destacar los que analizan cuestiones más específicas: las prácticas docentes (Foro 18), las relaciones entre la política y la sociedad (Foro 23) y el medio rural (Foro 25). Tal como podemos apreciar, el interés de alumnos y docentes se relaciona directamente con aspectos de la praxis escolar, si bien los problemas ciudadanos son los más demandados en los comentarios. Ello corrobora la importancia de relacionar los aspectos cotidianos con su formulación educativa. Una tarea compleja, pero al mismo tiempo apasionante.

Cuadro 4. Participación en los Foros: visitas y comentarios

\begin{tabular}{|c|c|c|c|c|c|c|c|c|}
\hline Foros & Título & $\begin{array}{l}\text { Moderador } \\
\text { debate/ foro }\end{array}$ & Ideas clave & $\begin{array}{l}\text { Evolución } \\
\text { 2015/16 } \\
\text { Coment. } \\
\end{array}$ & $\begin{array}{l}\text { Evolución } \\
\text { 2016/17 } \\
\text { Coment. } \\
\end{array}$ & $\begin{array}{l}\text { Evolución } \\
\text { 2017/18 } \\
\text { Coment. } \\
\end{array}$ & $\begin{array}{l}\text { Evolución } \\
\text { 2018/2019 } \\
\text { Coment } \\
\end{array}$ & $\begin{array}{l}\text { Evolución } \\
\text { 2019/2020 } \\
\text { Coment } \\
\end{array}$ \\
\hline Foro 14 & $\begin{array}{c}\begin{array}{c}\text { ¿Cómo formar al profesorado?: } \\
\text { Una aproximación internacional } \\
\text { http://geoforoforo2.blogspot.com/ }\end{array} \\
\frac{\text { 2013/02/foro-14-como-formar-al- }}{\text { profesorado-una.html }}\end{array}$ & Sara Fita & $\begin{array}{l}\text { Formación inicial } \\
\text { docente, Máster } \\
\text { Profesorado: } \\
\text { propuestas } \\
\text { innovación. }\end{array}$ & $82 / 82$ & $82 / 86$ & $86 / 95$ & $95 / 95$ & 95/96 \\
\hline Foro 15 & $\begin{array}{c}\begin{array}{c}\text { Las unidades didácticas en la } \\
\text { práctica escolar }\end{array} \\
\text { http://geoforoforo2.blogspot.co } \\
\frac{\mathrm{m} / 2013 / 04 / \text { foro-15-las-unidades- }}{\text { didacticas-en-la.html }}\end{array}$ & $\begin{array}{l}\text { Consejo } \\
\text { directivo }\end{array}$ & $\begin{array}{l}\text { Programación, } \\
\text { investigación - } \\
\text { innovación en el } \\
\text { aula. }\end{array}$ & $18 / 18$ & $18 / 23$ & $23 / 23$ & $23 / 25$ & 25 \\
\hline Foro 16 & $\begin{array}{c}\begin{array}{c}\text { Geografía y determinaciones } \\
\text { administrativas }\end{array} \\
\text { http://geoforoforo2.blogspot.co } \\
\frac{\text { m/2013/08/foro-16-la-geografia- }}{\text { y-las.html }}\end{array}$ & $\begin{array}{l}\text { Silvia Sousa, } \\
\text { Andrea Lastoria } \\
\text { Fabián Araya }\end{array}$ & $\begin{array}{c}\text { Evaluación externa, } \\
\text { homogeneización } \\
\text { del aprendizaje. }\end{array}$ & $50 / 50$ & $50 / 50$ & $50 / \mathbf{5 0}$ & $50 / 50$ & $50 / \mathbf{5 1}$ \\
\hline Foro 17 & $\begin{array}{c}\text { Educación ambiental y } \\
\text { planetaria / educação ambiental } \\
\text { e planetária } \\
\begin{array}{c}\text { http://geoforoforo2.blogspot.co } \\
\frac{\mathrm{m} / 2013 / 10 / \text { foro-17-educacion- }}{\text { ambiental-y.html }}\end{array}\end{array}$ & Olga Moreno & $\begin{array}{l}\text { Ciudadanía } \\
\text { planetaria, medio } \\
\text { ambiente, } \\
\text { investigación } \\
\text { educativa. }\end{array}$ & $45 / 57$ & $57 / 82$ & $82 / 82$ & $82 / 89$ & 89 \\
\hline Foro 18 & $\begin{array}{c}\begin{array}{c}\text { Las prácticas docentes: Opiniones } \\
\text { y Experiencias para innovar. } \\
\text { http://geoforoforo2.blogspot.com/ }\end{array} \\
\frac{2014 / 04 / \text { foro-18-las-practicas- }}{\text { docentes.html }}\end{array}$ & Santiago Herrero & $\begin{array}{c}\text { Experiencias } \\
\text { docentes, } \\
\text { innovación } \\
\text { educativa, papel } \\
\text { docente. } \\
\end{array}$ & $42 / 97$ & $97 / / 240$ & $240 / 242$ & $242 / 245$ & $245 / 248$ \\
\hline Foro 19 & $\begin{array}{c}\begin{array}{c}\text { El control del espacio y los } \\
\text { espacios de control. }\end{array} \\
\frac{\text { http://geoforoforo2.blogspot.com/ }}{2014 / 05 / \text { foro-19-el-control-del- }} \\
\frac{\text { espacio-y-los.html }}{}\end{array}$ & Xosé M. Souto & $\begin{array}{l}\text { El control de la } \\
\text { cultura escolar y } \\
\text { ciudadanía, } \\
\text { Participación } \\
\text { escolar, centro } \\
\text { escolar. }\end{array}$ & $17 / 18$ & $18 / 21$ & $21 / 21$ & 21 & 21 \\
\hline Foro 20 & $\begin{array}{c}\text { Las TIC y la Enseñanza } \\
\text { Geográfica de los problemas } \\
\text { sociales. } \\
\begin{array}{c}\text { http://geoforoforo2.blogspot.co } \\
\text { m/2014/11/foro-20-las-tic-y-la- }\end{array} \\
\text { ensenanza.html } \\
\end{array}$ & Yan Navarro & $\begin{array}{c}\text { TIC, Innovación, } \\
\text { problemas sociales, } \\
\text { Redes Sociales, } \\
\text { Mediación } \\
\text { pedagógica en Red. }\end{array}$ & $68 / 90$ & 90/154 & $154 / 156$ & $156 / 159$ & $159 / \mathbf{1 6 0}$ \\
\hline Foro 21 & $\begin{array}{l}\begin{array}{l}\text { Las salidas de Campo / Visitas } \\
\text { de Estudio. }\end{array} \\
\frac{\text { http://geoforoforo2.blogspot.co }}{\mathrm{m} / 2015 / 02 / \text { foro-21-las-salidas- }} \\
\frac{\text { de-campoa-visitas.html }}{}\end{array}$ & $\begin{array}{l}\text { Diego García } \\
\text { Monteagudo }\end{array}$ & $\begin{array}{c}\text { Didáctica } \\
\text { geografía, papel } \\
\text { docente, laboratorio } \\
\text { abierto, aprendizaje } \\
\text { significativo. }\end{array}$ & $159 / 387$ & $387 / 403$ & $403 / 441$ & $441 / 467$ & $467 / 507$ \\
\hline Foro 22 & $\begin{array}{c}\text { Aprendizaje de las ciencias } \\
\text { sociales desde el entorno } \\
\text { http://geoforoforo2.blogspot.co }\end{array}$ & Nancy Palacios & $\begin{array}{l}\text { Papel del medio } \\
\text { local en la }\end{array}$ & 87 & $87 / 108$ & $108 / \mathbf{1 1 3}$ & $113 / \mathbf{1 2 0}$ & $120 / \mathbf{1 3 3}$ \\
\hline
\end{tabular}

${ }^{17}$ La denominación original del proyecto es Nos Propomos!, que nace en el Instituto de Geografia e Ordenação do Território de la Universidade de Lisboa. Cuando llega a España adopta la terminología de Nosotros Proponemos y Nosaltres Proposem.

${ }^{18}$ Fita, S.; Claudino, S y Souto, X., $2018<$ http://www.ub.es/geocrit/b3w-1258.htm>. 


\begin{tabular}{|c|c|c|c|c|c|c|c|c|}
\hline & $\begin{array}{l}\mathrm{m} / 2016 / 01 / \text { foro-22-el- } \\
\text { aprendizaje-de-las-ciencias.html }\end{array}$ & & $\begin{array}{c}\text { organización } \\
\text { escolar }\end{array}$ & & & & & \\
\hline Foro 23 & $\begin{array}{l}\begin{array}{c}\text { Política, sociedad, educación y } \\
\text { ciencias sociales }\end{array} \\
\text { http://geoforoforo2.blogspot.co } \\
\begin{array}{c}\mathrm{m} / 2016 / 04 / \text { foro-23-politica- } \\
\text { sociedad-educacion-y.html }\end{array}\end{array}$ & $\begin{array}{l}\text { Jaeme Luiz } \\
\text { Callai }\end{array}$ & $\begin{array}{c}\text { Incidencia de la } \\
\text { política en los } \\
\text { espacios escolares } \\
\text { y sus contenidos } \\
\text { académicos } \\
\end{array}$ & 108 & $108 / \mathbf{2 5 2}$ & $252 / 261$ & $261 / 267$ & $267 / 270$ \\
\hline Foro 24 & $\begin{array}{c}\begin{array}{c}\text { Nós Propomos } \\
\text { http://geoforoforo2.blogspot.c }\end{array} \\
\frac{\frac{\text { om/2018/03/foro-24-nos- }}{\text { propomos-possibilidade- }}}{\underline{\text { da.html }}}\end{array}$ & $\begin{array}{l}\text { M.A Rodríguez, } \\
\text { S.Aparecida, } \\
\text { S. Claudino. }\end{array}$ & $\begin{array}{c}\text { Proyecto educativo, } \\
\text { participación } \\
\text { ciudadana, } \\
\text { innovación. }\end{array}$ & & & $1 / 348$ & $348 / 367$ & $367 / 368$ \\
\hline Foro 25 & 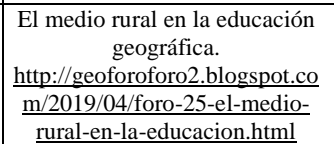 & $\begin{array}{l}\text { Diego García } \\
\text { Monteagudo, } \\
\text { Olga L Romero, } \\
\text { Luis Rivera }\end{array}$ & $\begin{array}{c}\text { El medio rural y la } \\
\text { formación de una } \\
\text { cultura crítica } \\
\text { ciudadana }\end{array}$ & & & & $1 / 229$ & $229 / 256$ \\
\hline Foro 26 & $\begin{array}{l}\begin{array}{c}\text { El coronavirus. Una experiencia } \\
\text { de aprendizaje }\end{array} \\
\text { http://geoforoforo2.blogspot.co } \\
\frac{\mathrm{m} / 2020 / 03 / \text { foro-26-el- }}{\text { coronavirus-una- }} \\
\text { experiencia.html\#comment-form }\end{array}$ & $\begin{array}{l}\text { Consejo } \\
\text { directivo }\end{array}$ & $\begin{array}{c}\text { La pandemia de la } \\
\text { covid-19 como } \\
\text { oportunidad para el } \\
\text { aprendizaje }\end{array}$ & & & & & $1 / 442$ \\
\hline
\end{tabular}

Fuente: Elaboración propia con datos del Geoforo (hasta 02/12/2020)

Los contenidos de los foros se sintetizan en diferentes artículos de recopilación y, también, de síntesis de problemas locales, como se ha podido comprobar en el Coloquio de Bogotá de marzo de 2019. En este mismo evento se ha acordado abrir un nuevo Geoforo en la Universidad Nacional Autónoma de México (UNAM), para facilitar el análisis de los contenidos expuestos en diferentes categorías conceptuales.

Para precisar el seguimiento analítico del Geoforo hemos decidido analizar los dos últimos foros que se han editado; son los numerados como 25 y 26 , sobre el medio rural y la pandemia respectivamente ${ }^{19}$.

\section{El Foro 25. El medio rural en la educación geográfica}

Tras la celebración en marzo de 2019 del I Coloquio Internacional sobre Enseñanza de la Geografía y Ciencias Sociales sobre los diez años del Geoforo Iberoamericano, se decidió abrir un nuevo foro ${ }^{20}$ sobre la didáctica de los espacios rurales. El debate fue propuesto desde la teoría de las representaciones sociales, pues como después se ha mencionado por algunos docentes universitarios, el modelo centro-periferia ahonda en la oposición entre lo urbano y lo rural, dificultándose una explicación de interdependencia bidireccional entre ambos espacios. Hasta el 15 de noviembre de 2020 se habían registrado 256 comentarios, fundamentalmente del alumnado de Valencia y Colombia, así como de profesorado en activo de Brasil y Perú (ver cuadro 5).

El análisis de las fechas de los comentarios que se han colocado, nos muestra la incidencia del profesorado universitario para animar al alumnado para exponer sus comentarios; es el caso de los docentes Diego García y Benito Campo en España, las profesoras Olga Romero y Liliana Rodríguez en Colombia y Silvia Sousa en Brasil. Sin duda, para que el Geoforo funcione en los debates es preciso animar al alumnado, pues las rutinas y hábitos conducen a realizar ejercicios

\footnotetext{
${ }^{19}$ Para el foro 25 seguimos un análisis que había realizado Diego García Monteagudo para el X Aniversario del Máster de Profesorado de Secundaria de la Universitat de València (25 al 30 de marzo de 2020), que finalmente no se pudo realizar por coincidir con el confinamiento domiciliario en España. Agradecemos su generosidad facilitando un texto inédito.

${ }^{20}$ Es el Foro 25.-El medio rural en la educación geográfica. Una realidad olvidada y necesaria para la formación ciudadana <http://geoforoforo2.blogspot.com/2019/04/foro-25-el-medio-rural-en-la-educacion.html>.
} 
para la clase, pero no a comunicar los resultados del estudio académico a otras personas que estudian en otras aulas del mundo iberoamericano. Esta constatación, que es lógica, supone romper las inercias de trabajar solo para un grupo reducido, que asume que el conocimiento escolar es poco valioso, pues no se difunde fuera de las paredes de las aulas. Animar al alumnado a difundir su conocimiento es una manifestación de las posibilidades de democratizar la enseñanza.

La situación de los espacios rurales en esos países participantes es reflejo de la representación social que se constata en cada uno de ellos y las diferencias en las preocupaciones son bastante distintas. El alumnado valenciano de cuarto curso del Grado de Maestro/a en Educación Primaria ha realizado un trabajo arduo de búsqueda bibliográfica para sintetizar el debate actual sobre los problemas que acontecen en estos espacios. Los futuros docentes mencionan la despoblación, la situación de desventaja de algunas escuelas rurales y ocasionalmente se apoyan en su experiencia en el período de prácticas para reflexionar sobre esa realidad escolar. Sin embargo, no predomina una visión crítica del currículo escolar, pues cuando mencionan los contenidos para la Educación Primaria no valoran el carácter descriptivo y la perspectiva morfológica del paisaje rural, un hecho que les condicionará la enseñanza de problemáticas socioambientales que propugnan en sus comentarios.

En cambio, desde Colombia y Brasil, se muestra la necesidad de aflorar las problemáticas de los espacios rurales, que se ocultan si no se fijan contenidos curriculares sobre esta temática. En las pruebas del Exame Nacional de Ensino Médio (ENEM), la profesora Silvia Sousa ha destacado los modelos de producción agroindustrial y el uso de agrotóxicos, con algunas críticas a la modernización del campo, lo que induce a afirmar que no se fomenta una visión bucólica de esos espacios. Sin embargo, esto contrasta con la situación en México, donde existe un gran desconocimiento de la realidad de las comunidades indígenas y la enseñanza de lo rural se subordina a lo urbano. Ese desinterés por la cultura y las formas de vida rurales también se ha destacado en Colombia, cuyos comentarios enfatizan la importancia de legitimar de poder a las escuelas rurales y mejorar el acceso a estos espacios para garantizar el desarrollo de una ciudadanía plena. También en Colombia se hace un análisis del impacto de la situación de los desplazados y, además, se hace una problematización del medio rural en el contexto de la globalización, en especial la escasa productividad económica de las explotaciones agropecuarias.

Las soluciones que se proponen desde los diversos países son escasas. El alumnado valenciano ha mencionado el trabajo del Grupo de Innovación Educativa L'Hort 2.0 ${ }^{21}$, a lo que se debería sumar el esfuerzo en la creación de unidades didácticas sobre los espacios rurales por parte del proyecto Gea-Clío ${ }^{22}$, además de trabajos locales elaborados en los centros escolares. En cualquier caso, el acercamiento a lo rural que se propugna desde este foro y se defiende por la proximidad del alumnado con el medio local, nos debe hacer reflexionar sobre la concepción pedagógica que ha prevalecido en esos proyectos desde la década de 1990 en España, pues se ha enseñado el espacio rural concebido con una escasa consideración de las vivencias del alumnado 23 .

\footnotetext{
$21<$ https://www.uv.es/hort/>.

${ }^{22}$ Se pueden consultar sus aportaciones en <http://socialsuv.org/gea-clio/>.

${ }^{23}$ Sobre este particular se puede consultar la Tesis doctoral de Diego García Monteagudo: La representación social del medio rural. Un análisis desde la geografía escolar, defendida en 2019 <http://socialsuv.org/2019/12/04/tesisdoctoral-de-diego-garcia-monteagudo/>.
} 
Cuadro 5. Participantes y opiniones registradas en el Foro 25

\begin{tabular}{|c|c|c|c|l|}
\hline Universidades & Personas & País & Comentarios & \multicolumn{1}{c|}{ Resumen } \\
\hline Valencia & 71 & España & 190 & Problemas en los espacios rurales \\
\hline Tolima & 17 & Colombia & 18 & Las dificultades de enseñar en la escuela rural \\
\hline UFJC, Bogotá & 15 & Colombia & 23 & $\begin{array}{l}\text { 1) lo global y lo local; 2) los fijos y los flujos; y 3) } \\
\text { el capital cultural y el capital económico en la } \\
\text { problematización del medio rural }\end{array}$ \\
\hline UNESP y USP & 6 & Brasil & 15 & La enseñanza en los espacios rurales \\
\hline San Marcos & 1 & Perú & 3 & Identidad del estudiante rural en su territorio \\
\hline UNAM & 2 & México & 3 & $\begin{array}{l}\text { La escasa importancia concedida a la situación de } \\
\text { la realidad rural }\end{array}$ \\
\hline
\end{tabular}

Fuente: Elaboración propia

Figura 5. Número intervenciones por países en el Foro 25

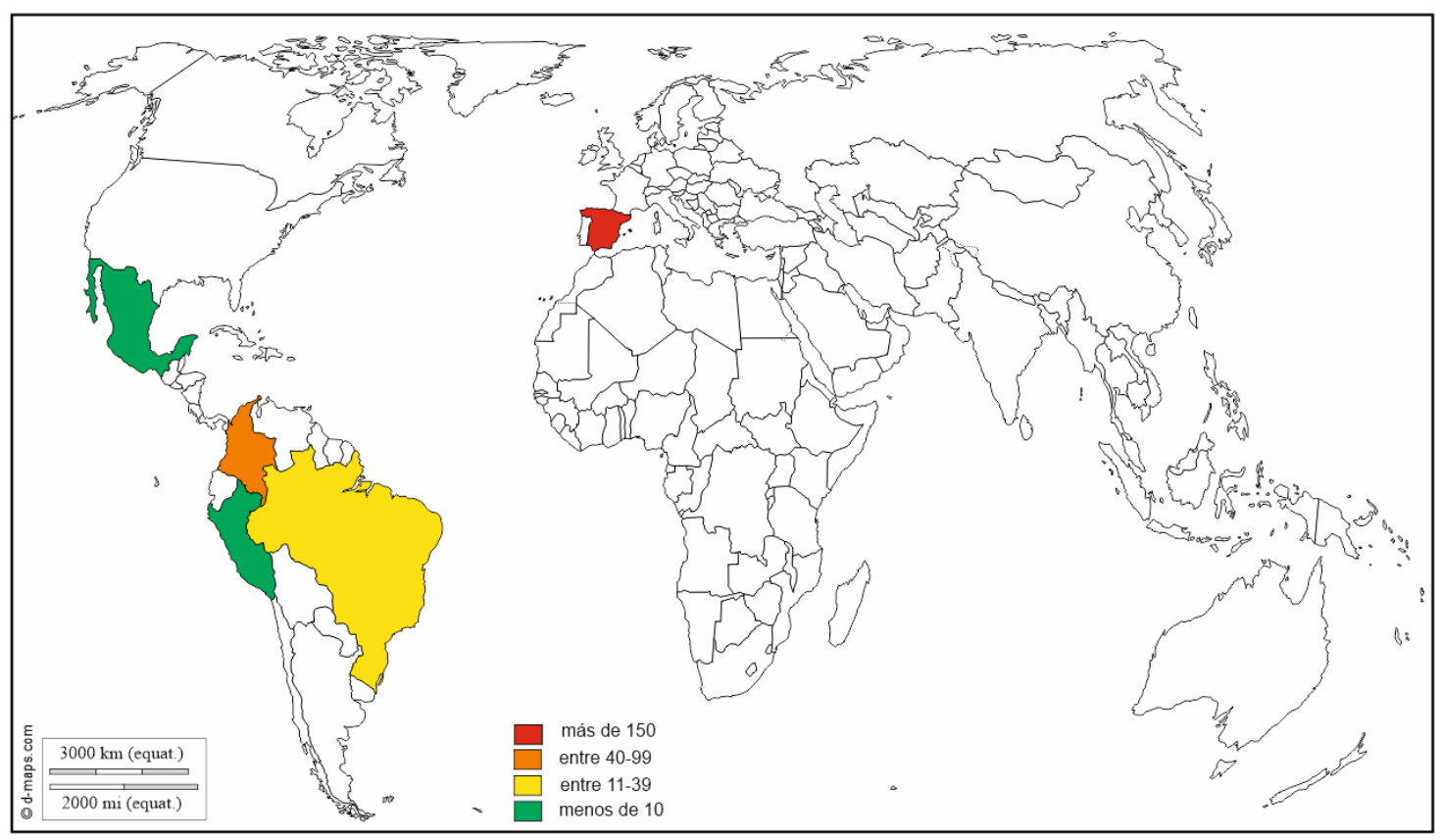

Fuente: Elaboración propia con datos del Geoforo. Plataforma Geocrítica UB ${ }^{24}$

\section{Foro 26: El Coronavirus. Una experiencia de aprendizaje}

En el caso del Geoforo Iberoamericano sobre Educación de la plataforma Geocrítica (UB) se han hecho casi 450 comentarios en los días finales de noviembre de $2020^{25}$, que se titulaba: El coronavirus. Una experiencia de aprendizaje. Este foro se inauguró el 20 de marzo a raíz de la expansión de la pandemia mundial. Observamos que los países que más han intervenido son España, seguido de Brasil y México. El traslado de este foro al nuevo Geoforo de la UNAM ha dado lugar a un incremento de las consultas, como se puede comprobar en la figura 7. En este caso, se observa el mayor número de visitas de cuatro países: España, Portugal, Brasil y México, clasificados correlativamente.

\footnotetext{
${ }^{24}$ También se puede acceder al Geoforo Iberoamericano mediante la Plataforma de Geocritica de la Universidad de Barcelona (UB) <http://www.ub.edu/geocrit/menu.htm>.

${ }^{25}$ El número total de comentarios varía respecto al que aparece automáticamente al final de cada foro, pues algunos están repetidos y otros borrados por el autor/autora que lo había colocado inicialmente.
} 


\section{Cuadro 6. Participantes/opiniones registradas en el Foro 26}

\begin{tabular}{|l|c|}
\hline \multicolumn{1}{|c|}{ Países } & Intervenciones \\
\hline Costa Rica & 1 \\
\hline España & 83 \\
\hline Brasil & 58 \\
\hline México & 16 \\
\hline Portugal & 4 \\
\hline Argentina & 1 \\
\hline Perú & 2 \\
\hline Colombia & 5 \\
\hline Reino Unido & 1 \\
\hline Sin especificar & 8 \\
\hline
\end{tabular}

Fuente: Elaboración propia

Figura 6. Comentarios realizados en el Foro 26

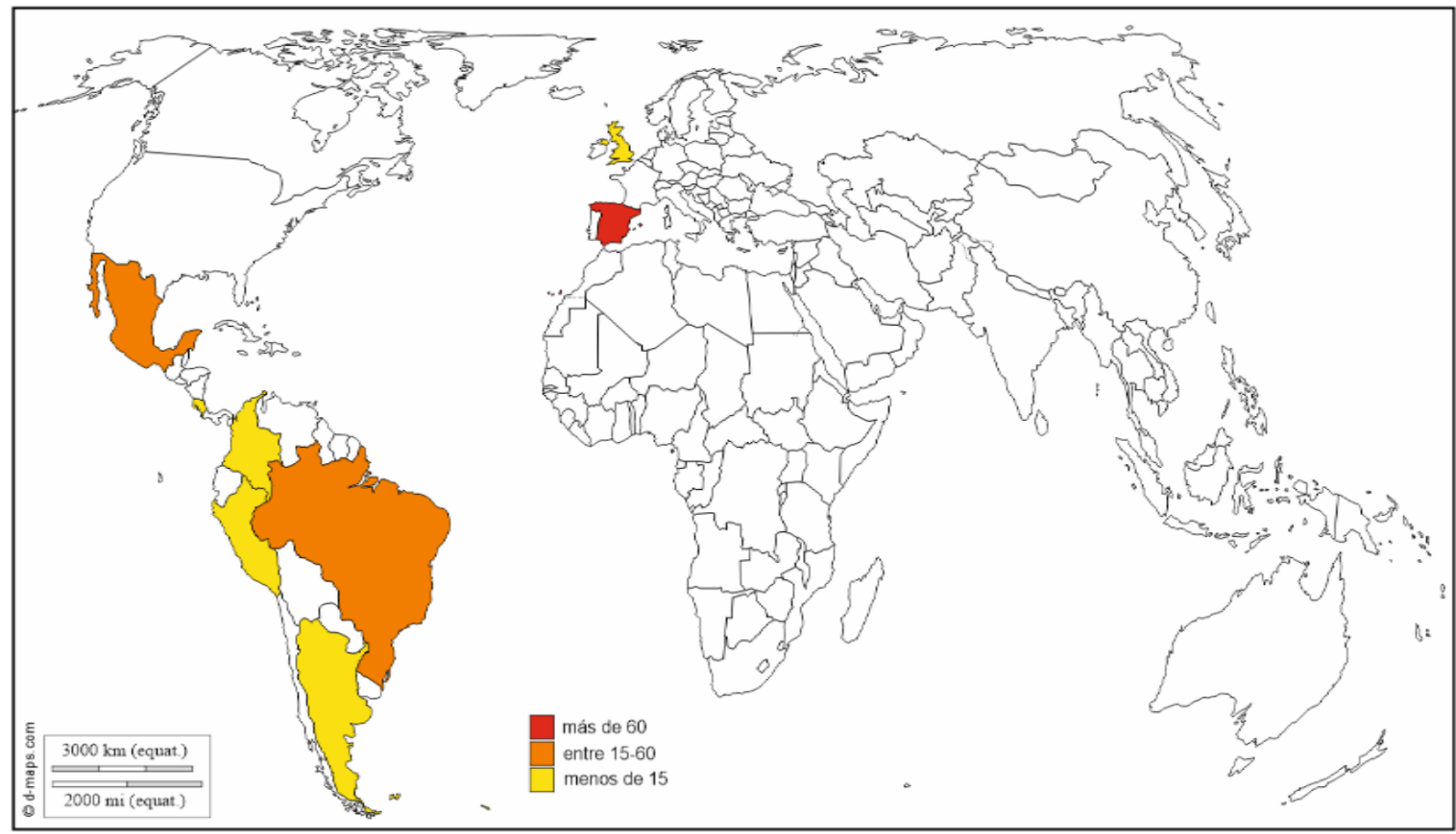

Fuente: Elaboración propia 
Figura 7. Visitas realizadas al foro 126 en la UNAM

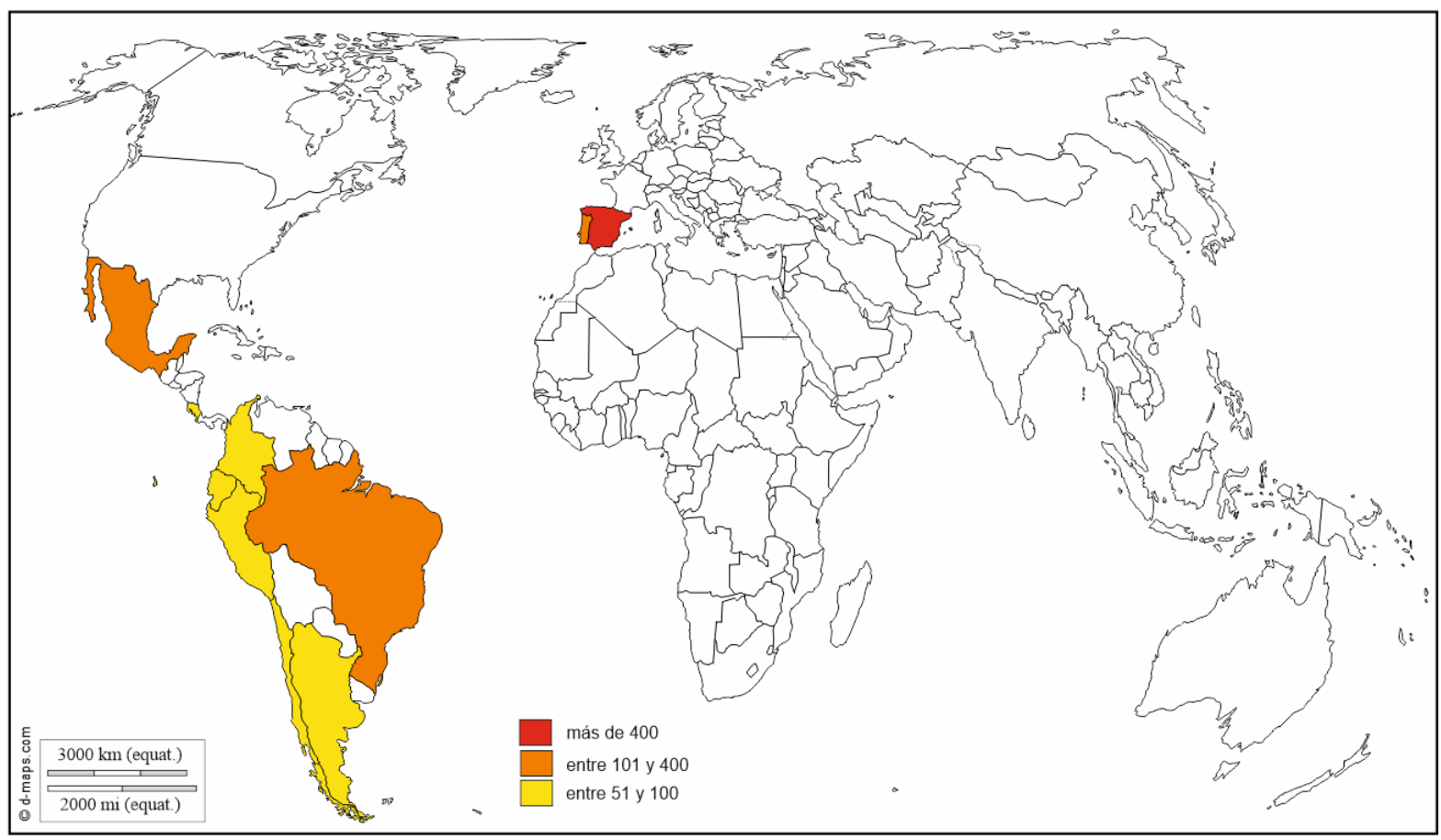

Fuente: Elaboración propia

Como se ha señalado, para poder analizar con más rigor los comentarios registrados en el Foro 26, sobre la pandemia, hemos abierto un Foro 126 en la Universidad Nacional de México (UNAM), que sintetizó los comentarios del blog anterior en diferentes categorías conceptuales. Ello nos permite analizar el contenido de opiniones y argumentos que afectan a ámbitos del saber que son semejantes.

El análisis de los contenidos del Foro 126, alojado en la UNAM de México, nos ha permitido analizar en qué aspectos ha destacado más la participación de las personas que emitieron sus opiniones. Tanto en los comentarios como en las visitas ha destacado, con más de dos terceras partes del total, el análisis de las definiciones, conceptos y consecuencias de la pandemia. Después, aparece la consulta del Manifiesto y, en mucha menor medida, el resto de categorías conceptuales. El Manifiesto, titulado "Las enseñanzas de la pandemia. Una propuesta para la actuación" 26 , se difundió en cuatro lenguas (castellano, portugués, catalán y gallego) y suscrito por doscientas personas del ámbito educativo. Más adelante se analiza su contenido.

\section{Las noticias}

Esta sección recoge la demanda de difusión de sucesos y eventos que se realizan en los lugares donde se ubican los principales grupos locales del Geoforo. Es una forma de compartir las producciones locales y difundir las expectativas y deseos del profesorado de los distintos núcleos territoriales del Geoforo. Las noticias más relevantes en estos años se centran en tres temáticas: Difusión de noticias relativas al coronavirus, noticias sobre jornadas internacionales del proyecto ¡Nós Propomos! y, finalmente, la noticia del fallecimiento de una persona que ha sido muy relevante en el análisis de los problemas sociales en las aulas escolares: Joan Pagès.

\footnotetext{
${ }^{26}<$ https://docs.google.com/document/d/1grFDfkqiwh2UGv_QqDMN29yj9D7bYketWztJENvU1sk/edit>.
} 
Cada año publicamos entre 20 y 25 noticias y las más visitadas son las que aparecen en el cuadro $7^{27}$.

Cuadro 7. Principales noticias visitadas en los años 2019 y 2020

\begin{tabular}{|c|c|c|c|}
\hline \multicolumn{2}{|c|}{ Año 2019 } & \multicolumn{2}{c|}{ Año 2020 } \\
\hline Noticias publicadas & Visitas & Noticias publicadas & Visitas \\
\hline $\begin{array}{c}\text { II Jornadas Internacionales del } \\
\text { Proyecto Nosotros proponemos }\end{array}$ & 75 & Debate Coronavirus -Aportaciones & 109 \\
\hline $\begin{array}{c}\text { Congreso Iberoamericano de } \\
\text { profesores de Nós Propomos en Perú }\end{array}$ & 59 & Artículo Noah Harari & 284 \\
\hline \multicolumn{2}{|c|}{} & Fallecimiento de Joan Pagès Blanch & 112 \\
\hline
\end{tabular}

Fuente: Elaboración propia

El resumen de los contenidos y su evolución diaria nos muestra el carácter puntual y anecdótico de esta sección frente a la constancia y mayor estabilidad en el caso de los foros. Como podemos observar, las oscilaciones son más continuas y el descenso más acusado coincide con el período estival en el hemisferio Norte, como sucedía en foros.

Figura 8: Evolución de las visitas y comentarios de la sección Noticias

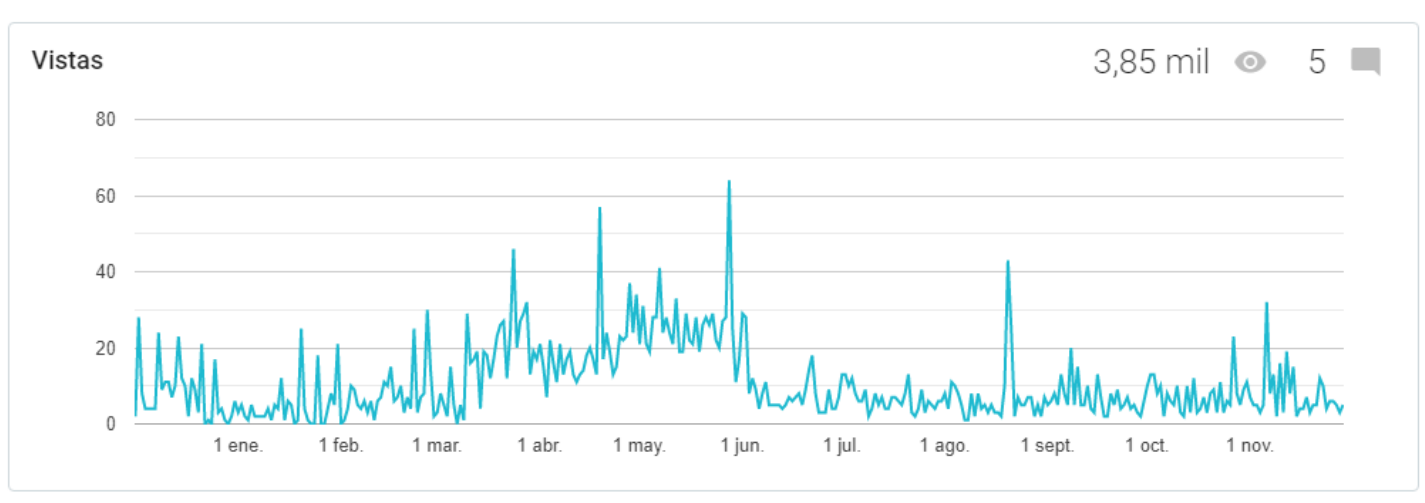

Fuente: Elaboración propia con Google Analytics

\section{Archivo del foro}

Igualmente, en el caso del Archivo del Foro hemos seleccionado los documentos que han recibido mayor número de visitas (ver cuadro 8$)^{28}$. Como podemos apreciar los documentos relativos a las Tesis doctorales y las informaciones complementarias de la pandemia son los documentos que han recibido más visitas. En este sentido hemos de manifestar nuestra satisfacción, pues se cumplen los objetivos que hemos venido resaltando en balances anteriores; esto es, que la sección de Archivo de Foro fuera útil para el alumnado universitario y jóvenes investigadores en su tarea de iniciar una base bibliográfica y teórica sobre la cual elaborar sus

\footnotetext{
${ }^{27} \mathrm{El}$ total de noticias publicadas se puede consultar en <http://geoforonoticias.blogspot.com/>.

${ }^{28} \mathrm{El}$ total de documentos de esta sección se puede consultar en <http://geoforodocumentos.blogspot.com/〉.
} 
programas de trabajo. Es el caso de la presentación, resumen y comentarios sobre la Tesis de Liliana Rodríguez, de la Universidad Distrital F.J. Caldas de Bogotá29.

Cuadro 8. Principales documentos de la sección Archivo del Geoforo

\begin{tabular}{|c|c|c|c|}
\hline \multicolumn{2}{|c|}{ Año 2019 } & Año 2020 \\
\hline Documento & Visitas & Documentos & Visitas \\
\hline $\begin{array}{c}\text { *Tesis Doctoral Liliana } \\
\text { Rodríguez Pizzinato }\end{array}$ & 97 & $\begin{array}{c}\text { *Debate Coronavirus: Aportaciones } \\
\text { *Noah Harari: El mundo después del } \\
\text { Coronavirus }\end{array}$ & $\begin{array}{c}320 \\
2633\end{array}$ \\
\hline
\end{tabular}

Fuente: Elaboración propia

\section{La Pandemia y la enseñanza de los problemas sociales}

La pandemia de coronavirus (COVID-19) ha provocado una crisis en todos los ámbitos. Una crisis sanitaria a nivel mundial sin precedentes que ha llevado a los Estados al límite de sus sistemas sanitarios y económicos. En la esfera de la educación, la pandemia dio lugar, en un primer momento, al cierre masivo de las actividades presenciales tanto en escuelas, institutos como universidades en más de 190 países ${ }^{30}$. Se pretendía así contribuir a reducir la propagación del virus. El impacto que esta situación, sin precedentes, causó en el ámbito educativo fue enorme. De la noche a la mañana el aprendizaje presencial se convirtió en aprendizaje en línea y alumnado, profesorado y familias tuvieron que adaptarse a continuar trabajando en estas nuevas condiciones para las que no estaban preparados. Meses después, en la medida de lo posible, las escuelas y demás centros educativos han reabierto en muchos países y la comunidad educativa se ha debido adaptar a una nueva normalidad en las aulas.

\section{Balance situación de la pandemia en diferentes lugares de Iberoamérica}

Las sesiones del día 31 de octubre de 2020 del Geoforo y Nos Propomos! han permitido debatir en conjunto las iniciativas que se han llevado a cabo en los diferentes países, a la vez que hemos analizado las semejanzas y diferencias de cada lugar ${ }^{31}$.

Como semejanzas entre los países representados en la reunión se destacan, en primer lugar, la poca claridad de los datos oficiales, lo que hace interesante el estudio de los mismos para poder analizar su evolución desde la academia. Por otra parte, se señala el contexto político como un factor relevante, tanto en la gestión de la salud pública como en el papel del Estado para combatir los problemas de la población más vulnerable. En este ámbito se analizan las posiciones partidistas y los acuerdos constitucionales.

El conocimiento geográfico de la pandemia resulta estratégico para explicar los problemas sociales que aparecen y cómo se resuelven en un tiempo, que ya no es sólo cronología inmediata, sino el tiempo de la ciencia y de las emociones personales. Dos temáticas que inciden en la definición del paradigma de la incertidumbre, que se enfrenta al canon tradicional del

\footnotetext{
${ }^{29}<$ http://geoforodocumentos.blogspot.com/2019/12/tesis-doctoral-liliana-rodriguez.html>.

${ }^{30}$ Ver Informe COVID-19 en Cepal-Unesco: <https://www.cepal.org/es/publicaciones/45904-la-educaciontiempos-la-pandemia-covid-19>.

${ }^{31}$ Ver <http://geoforodocumentos.blogspot.com/2020/11/reunion-del-geoforo-del-dia-31-de.html>.
} 
sistema escolar. En este sentido, la organización del sistema escolar es muy relevante para afrontar los problemas derivados de la debilidad de un sistema social que sólo busca la productividad. Por eso la opinión pública indica más la función de la custodia que la educativa. Se hace preciso analizar desde una perspectiva ciudadana y de acceso al derecho educativo, la instrumentalización de la educación con técnicas a distancia o enseñanza remota.

A nivel más específico, la reunión permitió conocer que en Colombia y en Perú el virus se ha centrado en zonas más urbanas, lo que ha generado que el efecto de la pandemia se haga sentir sobre todo en los colectivos más vulnerables situados en los barrios periféricos. Mientras que, en México, el virus ha afectado a la totalidad del territorio. Casos como Brasil, donde se destaca la concentración del virus en ciertos territorios, como São Paulo, hace pensar en cómo se relaciona la COVID-19 con la densidad de población. En el caso de Chile, se hace patente como la implicación política (sustitución de la Constitución de Pinochet por otra más democrática) ha generado las modificaciones en el papel de las instituciones públicas, como las que aparecen con la COVID-19. Desde Portugal, destaca la unidad de acción de los partidos políticos para diseñar una estrategia frente a la COVID-19, lo que contrasta con otros países, como España, Brasil o Perú. Por último, en España, se remarca como los datos revelan una clara intencionalidad, hacer responsables a la ciudadanía del problema, desplazando el foco de la responsabilidad de la gestión de las autoridades (contratación de médicos de atención primaria, rastreadores, instrumental sanitario...) a los comportamientos personales (colocarse la máscara, mascarilla o tapaboca, mantener las distancias, no salir al espacio público...).

\section{La gestión del manifiesto "Las enseñanzas de la pandemia. Una propuesta para la actuación”}

La situación extraordinaria que estamos viviendo desde el primer trimestre de 2020 motivó la redacción de un Manifiesto sobre las enseñanzas de la pandemia, sobre el futuro de la educación y de la convivencia a partir de la COVID-19, por parte de una serie de organizaciones: GeaClio $^{32}$ IRES $^{33}$ y Red- $14^{34}$ en España, Geopaideia ${ }^{35}$ en Colombia y el grupo ELO ${ }^{36}$ en Brasil.

El texto destaca el papel de la ciencia y la tecnología para combatir el virus; el análisis de la difusión de falsas noticias como generadoras de dudas e incertidumbre; del rol que una economía, principalmente de servicios, ha jugado a favor del aumento de los desequilibrios entre personas y territorios; y del riesgo medioambiental que todo esto supone.

Así mismo, el manifiesto también hace referencias históricas sobre las pandemias, ya que han sido un fenómeno recurrente y matiza que la actual tiene como novedad el alud de información, muchas veces contradictoria y sujeta a intereses ocultos de algunas personas y grupos. De ahí que los firmantes del manifiesto vean la necesidad de que la pandemia sirva para trabajar, desde el campo educativo y cultural, la comparación de semejanzas. Además, exponen 10 principios para desarrollar a nivel profesional, social y personal que marcan una clara metodología de trabajo y en compromiso con la sociedad.

\footnotetext{
$32<$ http://socialsuv.org/gea-clio/>.

$33<$ https://www.redires.net/?q=quienes_somos $>$.

$34<$ https://red14.net/es/inicio/>.

$35<$ http://geopaideia.org/>.

$36<$ https://falagrupoelo.blogspot.com/>.
} 
Los 10 principios tienen como base la Declaración Universal de los Derechos Humanos; las teorías sólidas de las ciencias sociales; los principios de sostenibilidad y economía circular; la selección de problemas sociales e incertidumbres humanas, como elementos clave en los contenidos educativos a impartir en las aulas; y el compromiso de impulsar el conocimiento crítico a partir de una cautelosa selección de las fuentes de información y una el rechazo a la difusión de bulos.

El Manifiesto se difundió en agosto entre la comunidad educativa con la intención de recabar apoyos y, una vez cumplido este objetivo, darle máxima difusión. Desde agosto hasta 31 de octubre 176 personas de procedencia diversa han firmado el documento, como puede verse en la figura 7. El mayor número de firmantes son de España, Portugal, Colombia y Brasil, siendo menor la presencia de otros países iberoamericanos, lo que corrobora la influencia de las redes educativas en la difusión de este manifiesto, con sus tareas adjuntas.

Figura 9. Firmantes del manifiesto de la pandemia por países

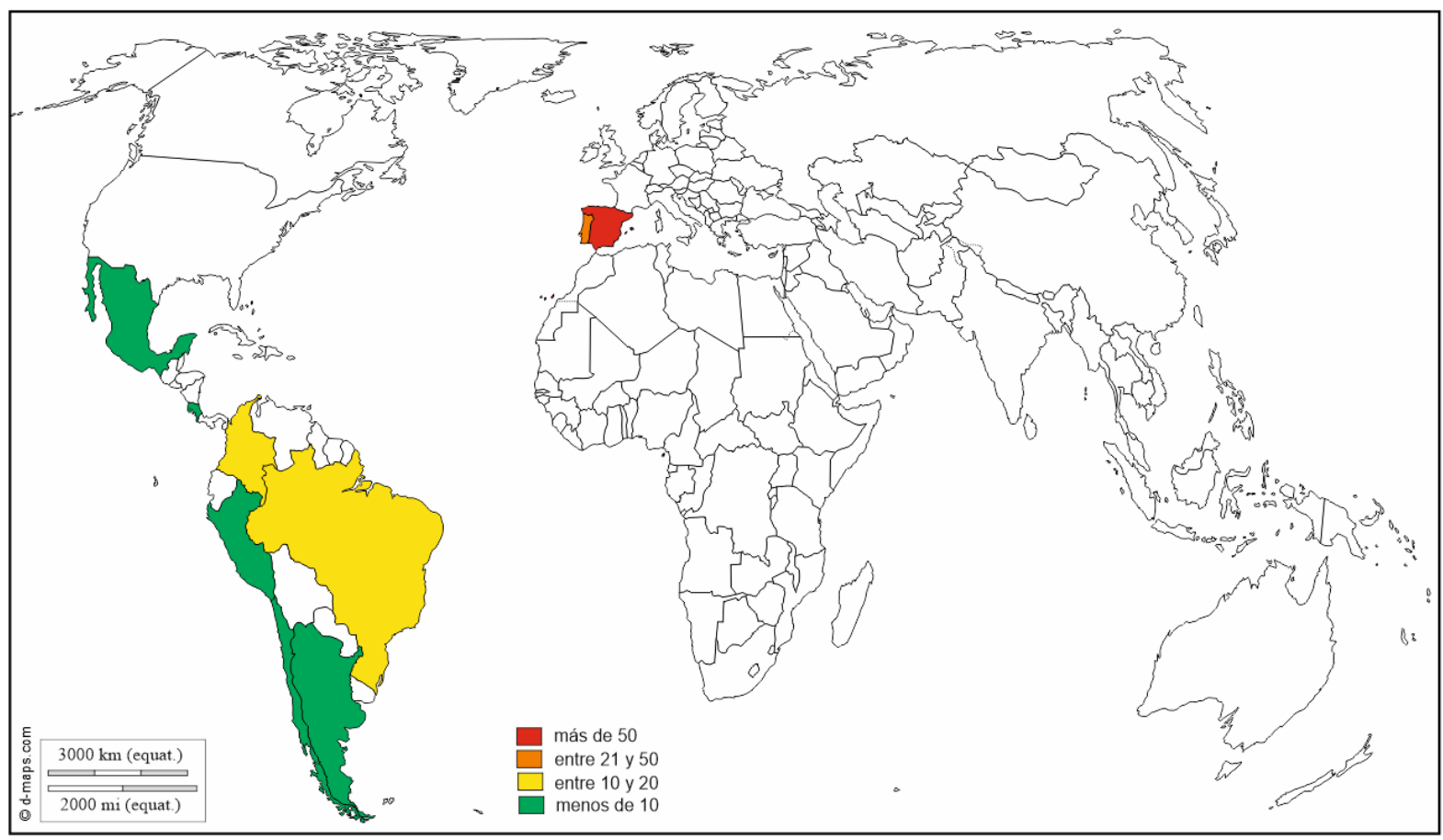

Fuente: Elaboración propia

Pero además de la procedencia geográfica es relevante destacar la identificación de los firmantes. Observamos que la mayoría de los firmantes procede de instituciones universitarias con cerca del $60 \%(57,6 \%)$ de las firmas recogidas hasta final de octubre de 2020. Ello significa que desde el Geoforo es más fácil llegar a las instituciones universitarias que al resto de instituciones educativas escolares, además de las resistencias y desconfianzas que se genera en otros ámbitos académicos respecto a la utilidad de este tipo de manifiestos. 


\section{Cuadro 9. Identificación de los Firmantes del manifiesto de la pandemia}

\begin{tabular}{|c|c|}
\hline Enseñanzas & $\mathbf{N}^{\mathbf{0}}$ de firmantes \\
\hline Infantil y Primaria & 8 \\
\hline Secundaria & 52 \\
\hline Universidad & 98 \\
\hline Grupos e instituciones escolares & 12 \\
\hline
\end{tabular}

Fuente: Elaboración propia

El Manifiesto, que se puede encontrar en cuatro idiomas (gallego, catalán, portugués y castellano), es una declaración de intenciones por parte de los firmantes de cómo aprovechar la pandemia como una oportunidad de aprendizaje. En el Manifiesto se plantea la necesidad de afrontar el estudio de la pandemia tanto desde el plano personal como el colectivo, lo que implica tener en cuenta tanto las repercusiones a nivel personal como las consecuencias sociales. Los firmantes, implicados en la difusión de la cultura crítica, invitan a otras asociaciones y personas a manifestar sus expectativas sobre el futuro de la humanidad en un marco de la convivencia ciudadana. Y adquieren el compromiso ético de dar a conocer sus argumentos.

\section{El impacto de la pandemia en nuestro trabajo y en la socialización}

Sabemos que una de las principales consecuencias que está teniendo la pandemia es el cambio en nuestra manera de interactuar y de relacionarnos. Y esto se ha reflejado en las prácticas docentes. Así, a las rutinas del aula, se le han sumado las medidas de control sanitario como pueden ser toma de temperatura, recordatorio de limpieza de manos, vigilancia de colocación de mascarillas o de la distancia de seguridad. Esto ha generado que el profesorado asuma nuevas funciones, no solo en el aula sino en todo el centro de trabajo que condicionan su práctica diaria.

Las relaciones profesorado-alumnado implican una menor proximidad física y las relaciones entre el profesorado también (menor contacto próximo diario e incremento del contacto online). Esto no es único en el ámbito de la educación, sino que en la mayoría de trabajos encontramos nuevas pautas que en muchos casos tienden al aislamiento. Vemos pues, que la pandemia ha cambiado nuestra forma de socializar, sujeta ahora a una mayor comunicación a través dispositivos electrónicos o manteniendo distancias. Las redes sociales han servido como nuevo espacio de socialización durante la pandemia, aplicaciones como Instagram, Twitter, Zoom, Skype, Whatsapp, Google Meet, entre otras, han sido los nuevos canales de interacción. Estas herramientas han permitido crear nuevas vías de comunicación y también de trabajo.

\section{Las enseñanzas de la pandemia}

El cierre de las instituciones educativas al inicio de la pandemia y la posterior reapertura ha sido aprovechado por muchos docentes como una oportunidad de aprendizaje para trabajar lo vivido y generar interesantes propuestas de trabajo desde la cooperación. 


\section{Propuestas de tareas a partir del manifiesto}

Un ejemplo es la propuesta de tareas a partir del manifiesto que conjuntamente crearon un amplio número de docentes. En estas tareas destacan las propuestas para diferentes niveles: profesorado, alumnado universitario, alumnado preuniversitario (17/19 años), alumnado de educación secundaria y alumnado de educación primaria de entre 10-11 años ${ }^{37}$.

La propuesta de tareas para el profesorado tiene como objetivo dar a conocer el manifiesto entre los docentes para que lo puedan trabajar en el aula y así fomentar el intercambio de experiencias entre el profesorado y el alumnado y dejar constancia en el Foro 26 y en el $126^{38}$. De esta manera se busca generar un discurso crítico al margen de los intereses mediáticos e inmediatos. Además, se anima a participar al profesorado confeccionando un listado de webs y artículos que, por su rigurosidad, puedan resultar interesantes como fuentes de información sobre la pandemia.

A partir de esta propuesta de tarea para los/las docentes, se diseñaron unas actividades para el alumnado adaptadas por niveles. Así para el alumnado universitario y pre-universitario, la propuesta plantea un trabajo de análisis de dos noticias por grupos a partir de modelo (cuadros 10 y 11).

\section{Cuadro 10. Modelo para comentario (nivel universitario)}

\section{Título y fuente de la noticia}

2. Identificar el problema y ver cómo afecta a vuestra localidad

3. Comparar información: establecer números relativos de contagios, muertes... índices, tasas. Seleccionar historias personales

4. Interpretar información, tanto cuantitativa como cualitativa para establecer un resumen de la situación local

5. Desarrollar generalizaciones para intuir posibles conjeturas

6. Evaluar alternativas respecto a la solución hipotética

7. Determinar los hechos para mostrar los argumentos que se defienden

8. Verificar el impacto sobre la vida de algunas personas concretas, indicando ejemplos específicos

Fuente: Elaboración propia sobre propuesta de Benito Campo

Cuadro 11. Modelo para comentario (nivel pre-universitario)

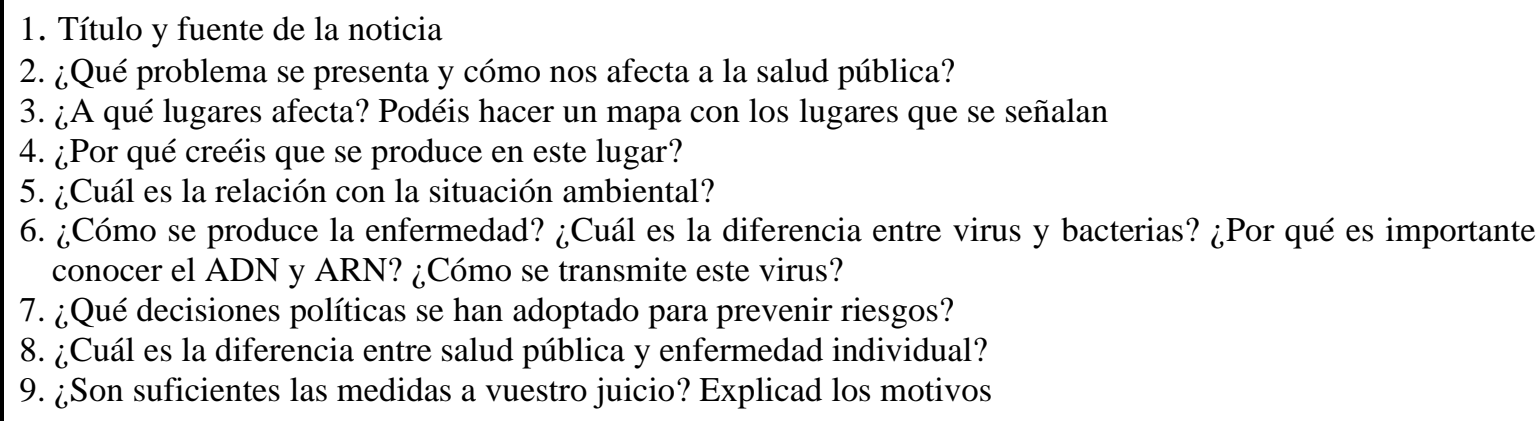

Fuente: Elaboración propia sobre propuesta de Benito Campo

\footnotetext{
37 <https://drive.google.com/drive/folders/1CjmuDDJ-j44CXmTbFNSOlfM7ZIGOIwtu>

${ }^{38}$ Nos referimos al Geoforo Iberoamericano ubicado en la plataforma Geocrítica de la Universitat de Barcelona con el Foro 26 <http://geoforo.blogspot.com/>; así como también al Geoforo situado en la plataforma de la Universidad Nacional Autónoma de México, UNAM <http://www.geoforo.unam.mx/secforo/index.php>con el foro 126
} 
Como observamos, una de las diferencias es que en el nivel preuniversitario se proponen actividades interdisciplinares en especial en relación con Biología, fomentando de esta forma el trabajo colaborativo en la escala de centro escolar.

Las propuestas de tareas para alumnado de educación secundaria están pensadas para edades comprendidas entre 13-14 años (cuadro 12). Buscan fomentar el trabajo de investigación sobre el medio local y la interdisciplinariedad. A partir de una noticia (de televisión, radio, prensa...) que el profesorado presenta a un pequeño grupo esta se debe analizar siguiendo el modelo planteado para posteriormente hacer entrevistas o encuestas. El modelo de estas encuestas debe ser sencillo, pero dependerá de cada grupo de alumnos. Las preguntas versarán sobre la presencia o no de personas que se han infectado (cómo han pasado la enfermedad) y sobre las expectativas ante la pandemia (miedos, cómo ha afectado a las relaciones sociales) y finalmente sobre el debate de las medidas adoptadas (cómo juzgan la situación política).

\section{Cuadro 12. Modelo para comentario (nivel Secundaria)}

1. Título y fuente de la noticia

2. ¿Qué problema se presenta? Indicad la relación de este problema con la pandemia

3. Hacer un resumen con la presencia de otras pandemias en la historia de la humanidad. Podéis hacer un friso cronológico

4. ¿A qué grupos de edad, género y condición social afecta más y menos? Recoged las impresiones de algunas personas entrevistadas

5. Explicad la repercusión en la mortalidad, ingresos hospitalarios y conocimiento de la enfermedad.

6. ¿A qué lugares afecta? Podéis hacer un mapa con los lugares y colocar fotos de los mismos.

7. ¿Por qué creéis que se produce en este lugar?

8. ¿Por qué creéis que afecta más a unas personas que a otras?

9. ¿Qué decisiones políticas se han adoptado para prevenir riesgos? Indicad si hay personas que se han opuesto a estas medidas.

10. Explicad el debate sobre las medidas sanitarias que se han adoptado. Indicad la repercusión en la salud pública

11. ¿Qué es una vacuna? ¿Es la solución para el problema? Indicar otras vacunas que han existido en la historia de la humanidad

Fuente: Elaboración propia sobre propuesta de Benito Campo

La propuesta de tarea para el alumnado de Educación Primaria (cuadro 13) se centra en fomentar la observación directa de situaciones de clase y del ámbito familiar. Es una propuesta para final de etapa, pero se podría adaptar en todos los cursos escolares.

Cuadro 13. Modelo para comentario (nivel Educación Primaria)

En el centro escolar habrás visto que hay diferentes usos y actividades como consecuencia de la pandemia. Vamos a analizar algunas cuestiones y hacer un pequeño dossier para colgar como mural en la clase.

1. ¿Qué cambios existen en las clases? Haced una foto de la clase y compararla con la que recordáis de otros años

2. ¿Cómo se hace la entrada al centro escolar? ¿Qué diferencias hay con el acceso de otros años? ¿qué molestia supone entrar de esta manera?

3. ¿Cómo se utilizan los patios y gimnasios? ¿Podéis utilizar los vestuarios? ¿Por qué?

4. Cómo sabéis se habla de una pandemia. Definid este concepto y diferenciarlo de una enfermedad. Con ayuda del profesor/a, libros y páginas web definir otras pandemias que existen en estos momentos

5. Cómo afecta la pandemia a las personas de casa. ¿han tenido que trabajar de forma diferente? ¿Han perdido el trabajo? ¿Qué miedos tienen? ¿Cómo se desplazan dentro de la ciudad o pueblo?

6. ¿Cuál es la medida que más os afecta a vuestra vida diaria?

7. ¿Cuáles son vuestras propuestas para acabar con la pandemia? 


\section{Propuestas de tareas desarrolladas en distintos centros}

La pandemia ha motivado a los maestros a crear propuestas didácticas para trabajar el momento que estamos viviendo con sus alumnos. Todas ellas coinciden en la necesidad de comprender, junto al alumnado, las nuevas normas para protegernos del coronavirus. Pretenden que estas normas no sean percibidas como una imposición externa que debe ser obedecida, sino que a partir del debate estas normas sean percibidas como necesarias desde el punto de vista colectivo. Y reforzar los lazos con las familias, evitando que el distanciamiento físico sea un impedimento en la comunicación. Tenemos la oportunidad de salir de la rigidez de los libros de texto y detenernos a pensar sobre lo que es relevante aprender y de esta forma priorizar. La escuela debe trabajar qué ha pasado y qué está pasando en estos momentos para no estar desconectada de la realidad. Hemos seleccionado algunos ejemplos de centros escolares de la Comunidad Valenciana para ilustrar las posibilidades de trabajo en las aulas.

Infantil

En el nivel de infantil disponemos del ejemplo de las propuestas llevadas a cabo en el CEIP Ausias March de Llutxent. Se ha realizado un acompañamiento emocional durante el confinamiento a partir de una guía para las familias. Se consideró que estas eran clave, ya que debían asumir un rol muy activo en estos momentos. Se han trabajado situaciones a partir de los cuentos. Durante el confinamiento la propuesta del colegio pretendía que los niños y niñas expresaran cómo se sentían ante la nueva situación a partir de la lectura de diferentes cuentos (algunos inventados por el profesorado, ejemplo "El cuento del coronavirus"; otros para trabajar las emociones como "El monstre de colors"). Además, describían las recomendaciones una vez abiertos los colegios para conocer las nuevas medidas de prevención, explicando nuevos conceptos como "grupo burbuja" y continuar trabajando las emociones a través del cuento.

Observamos, en la etapa de infantil, que la propuesta dio especial importancia a la gestión de las emociones a través del recurso del cuento y buscaba dar respuestas a todas las preguntas y dudas que les pudieran surgir tanto en casa como en el colegio.

\section{Primaria}

La propuesta de aula para primer ciclo de primaria, tal como se indicó consistía en trabajar las normas de higiene, limpieza personal y autonomía, con los contenidos del currículum de Ciencias Naturales. Al mismo tiempo, se estudiaba el tiempo pasado, a partir del calendario de aula que quedó detenido en el mes de marzo (Ciencias Sociales). Se pretendía conocer mejor las vivencias del alumnado durante el periodo de confinamiento a partir del dibujo (dibujar alguna situación que les ha gustado y otra que no del tiempo que estuvieron sin venir al colegio): además de aprovechar los dibujos para fomentar la comunicación con el alumnado y crear lazos de confianza ${ }^{39}$.

En el CRA Serra del Benicadell, Montitxelvo, se ha desarrollado un conjunto de tareas para el tercer ciclo de Educación Primaria. Consistía en desarrollar un proyecto de investigación planteado conjuntamente con el alumnado sobre hechos relevantes del 2020. Se elaboró un mapa conceptual a partir de la pregunta “¿Qué queremos saber?”. Ello facilitó el estudio del conocimiento de la COVID-19 a partir de preguntas planteadas por el alumnado (¿cuántas

\footnotetext{
${ }^{39}$ Este trabajo ha sido redactado por la profesora Carla Aparici y se ha colgado en la misma plataforma que hemos indicado en nota con enlace específico:
} <https://docs.google.com/document/d/1Jf6mm7uauaRq23CQN1RvCt4PzO77-Ohb/edit〉. 
muertes ha habido?, ¿cómo son las medidas de seguridad en otros países?, ¿cómo se puede mejorar la comunicación ahora que llevamos las mascarillas? ...). También tenemos ejemplos de propuestas del centro Mediterrania de Xàbia. La planificación de las Unidades Didácticas de ciencias de todos los cursos se ha realizado desde el punto de vista local, con la situación de crisis sanitaria han aprovechado para crear aulas al aire libre y planificar más salidas a la naturaleza y al ámbito local.

Secundaria

Algunos ejemplos fueron expuestos en el Foro 26, como la propuesta para Primero de la ESO (12 años de edad) en un ámbito sociolingüístico, que consistía en el diseño de un Proyecto sobre la distribución del ser humano por la Tierra, con tareas sobre problemáticas concretas derivadas del impacto humano sobre el planeta. Una de las tareas trabajaba la pandemia desde el punto de vista medioambiental (cómo el confinamiento redujo la emisión de $\mathrm{CO}^{2}$, disminución de plásticos, aguas más limpias...).

En el Instituto de Secundaria Arabista Ribera (alumnado con edades de 12 a 16 años), de la localidad de Carcaixent, se desarrolló una dinámica de conocimiento y confianza con la tutoría intentado superar las dificultades que supone relacionarse con los compañeros guardando distancias de seguridad y con el rostro cubierto por las mascarillas. La dinámica "Tutoría por la cara" consiste en descubrirse el rostro delante de los compañeros protegidos por una pantalla y hablar sobre uno mismo y sobre aspectos de su vida.

Otras propuestas son más disciplinares, para trabajar la Geografía Humana (entre 13 y 18 años), como la realizada por un compañero de Gea-Clío, Juan Ramón Durá ${ }^{40}$. Se programó el análisis de los efectos de la COVID-19 a partir de elementos claves como la situación sanitaria de los países con medicamentos, recursos económicos, cobertura sanitaria pública, existencia de hospitales, inversión en salud a partir de conceptos como el PIB o el IDH. Se desarrolló la observación, indagación y análisis de una problemática como es la expansión de la COVID-19 desde el punto de vista geográfico. Esta finalidad se concretó en el estudio de conceptos básicos como natalidad, mortalidad, fecundidad, población absoluta, densidad de población...y del comentario de tablas estadísticas sobre densidad de población por CCAA, casos confirmados por PCR por CCAA, etc. Un ejemplo de tarea consistía en analizar las diferencias entre países ricos y países pobres en cuanto a régimen demográfico, población, muertos e infectados por COVID. Con ello se buscaba obtener conclusiones sobre las relaciones entre la mortalidad de la COVID -19 y las características de la población de estos países. El cuadro 14 sintetiza este tipo de actividades que muestra cómo se puede relacionar directamente el currículo escolar de la Secundaria con el estudio de la pandemia ${ }^{41}$.

\footnotetext{
$40<$ https://drive.google.com/drive/folders/1CjmuDDJ-j44CXmTbFNSOlfM7ZIGOIwtu〉.

41 También sobre tareas en Secundaria podemos consultar la noticia <http://geoforonoticias.blogspot.com/2020/11/trabajos-escolares-sobre-la-pandemia.html> donde se da cuenta de los trabajos realizados en un centro de Benidorm (España) bajo la dirección de Rafael Olmos.
} 
Cuadro 14. Ejemplos de documentos sobre la pandemia para trabajar en Secundaria

\begin{tabular}{|c|c|c|c|c|c|c|c|}
\hline Països & $\begin{array}{c}\text { Sistema } \\
\text { sanitari } \\
\text { public } \\
\text { potent }\end{array}$ & $\begin{array}{l}\text { Pobresa } \\
\text { del país }\end{array}$ & $\begin{array}{c}\text { Nombre } \\
\text { de } \\
\text { metges } \\
\text { per } \\
\text { habitant }\end{array}$ & Medicaments & $\begin{array}{c}\text { Gestió } \\
\text { sanitaria } \\
\text { del país }\end{array}$ & $\begin{array}{l}\text { Hospitals } \\
\text { i material } \\
\text { sanitari }\end{array}$ & $\begin{array}{c}\text { Contactes } \\
\text { socials }\end{array}$ \\
\hline Alemanya & & & & & & & \\
\hline Itàlia & & & & & & & \\
\hline EEUU & & & & & & & \\
\hline Espanya & & & & & & & \\
\hline Brasil & & & & & & & \\
\hline Índia & & & & & & & \\
\hline
\end{tabular}

Fuente: Elaboración propia sobre propuesta de Juan Ramón Durá

\begin{tabular}{|c|c|c|c|c|c|c|c|}
\hline $\begin{array}{c}\text { Datos a } \\
09 / 09 / 2020\end{array}$ & $\begin{array}{c}\text { Población en } \\
\text { millones de } \\
\text { habitantes } \\
\end{array}$ & $\begin{array}{c}\text { Número } \\
\text { de } \\
\text { infectados }\end{array}$ & $\begin{array}{c}\text { Infectados } \\
\text { por } \\
\text { millón } \\
\end{array}$ & $\begin{array}{c}\text { Ranking } \\
\text { Infectados } \\
\text { por millón }\end{array}$ & $\begin{array}{c}\text { Número } \\
\text { de } \\
\text { fallecidos }\end{array}$ & $\begin{array}{c}\begin{array}{c}\text { Fallecidos } \\
\text { por } \\
\text { millón }\end{array} \\
\end{array}$ & $\begin{array}{c}\text { Ranking } \\
\text { Fallecidos } \\
\text { por millón } \\
\end{array}$ \\
\hline Mundo & $7.792,66$ & 28.111 .887 & $3.607,48$ & & 909.570 & 116,72 & \\
\hline Estados Unidos & 331,38 & 6.559 .509 & $19.794,52$ & $2^{o}$ & 195.590 & 590 & $4^{\circ}$ \\
\hline India & $1.382,6$ & 4.494 .389 & $3.250,68$ & $10^{\mathrm{a}}$ & 75.238 & 54,42 & $10^{\circ}$ \\
\hline Brasil & 212,85 & 4.494.332 & $19.729,07$ & $3^{\circ}$ & 128.653 & 604,43 & $3^{\circ}$ \\
\hline Rusia & 145,95 & 1.046 .370 & $7.169,37$ & $8^{\circ}$ & 18.263 & 125,13 & $9^{\circ}$ \\
\hline Perú & 33,06 & 702.776 & $21.257,59$ & $1^{\mathrm{o}}$ & 30.236 & 914,58 & $1^{\mathrm{o}}$ \\
\hline Colombia & 50,99 & 686.856 & $13.470,41$ & $4^{\circ}$ & 22.053 & 432,50 & $6^{\circ}$ \\
\hline México & 12919 & 647.507 & $5.012,05$ & $9^{\circ}$ & 69.09 & 534,83 & $5^{\circ}$ \\
\hline Sudáfrica & 59,45 & 642.431 & $10.806,24$ & $7^{\circ}$ & 15.168 & 255,14 & $7^{\circ}$ \\
\hline España & 46,76 & 543.379 & $11.620,59$ & $5^{\circ}$ & 29.628 & 633,62 & $2^{\circ}$ \\
\hline Argentina & 45,28 & 512.293 & $11.313,89$ & $6^{\circ}$ & 10.713 & 236,59 & $8^{\circ}$ \\
\hline $\begin{array}{l}10 \text { países con } \\
\text { más infectados } \\
\text { por millón }\end{array}$ & $2.437,51$ & 20.034 .842 & $8.219,39$ & & 594.637 & 243,95 & \\
\hline$\%$ Totales & $31,28 \%$ & $71,27 \%$ & & & $65,38 \%$ & & \\
\hline
\end{tabular}

Fuente: Elaborada con datos extraídos de Worldometers

\section{Las voluntades de innovación y las posibilidades reales}

La pandemia ha generado que grupos de trabajo como Gea-Clio ${ }^{42}$, Capgirem l'ESO ${ }^{43}$, Grupo Estudio da Localidade en Ribeirão Preto ${ }^{44}$ (Grupo ELO) hayan visto una oportunidad para plantear diferentes propuestas ligadas a la innovación. Estos grupos de trabajo reivindican el estudio a través de problemas, cuando más ligados a la realidad mejor. Así, grupos como Capgirem l'ESO abogan por repensar el sistema y sustituir las asignaturas por problemas. Cabe decir que España es uno de los estados en el que la flexibilidad en la organización de los tiempos de aprendizaje es prácticamente inexistente ${ }^{45}$, lo cual dificulta este tipo de iniciativas.

Una oportunidad de cambio ha venido de la mano de la situación sanitaria actual en la Comunidad Valenciana, que a partir de la Resolución del 29 de mayo sobre la organización del primer curso de la ESO para el siguiente curso, introdujo la organización por ámbitos de conocimientos, integrándose las materias en ellos con la finalidad de facilitar la transición de sexto de Primaria a $1^{\circ}$ de la ESO. La estructura de los ámbitos permite alargar los tiempos de trabajo al agrupar asignaturas y horas e introducir la docencia compartida. Esto permite llevar a cabo prácticas para las que se requiere más tiempo y que en las tradicionales sesiones de 55

\footnotetext{
$42<$ http://socialsuv.org/gea-clio/>.

$43<$ https://sites.google.com/view/capgirem/inici>.

$44<$ https://falagrupoelo.blogspot.com/>.

${ }^{45}$ Ver Gabaldón y Oriol, 2016. <https://doi.org/10.7203/CREATIVITY.1.12062>.
} 
minutos no son posibles, hablamos de ver un documental o película completa y establecer un debate, hacer tertulias literarias, exposiciones orales de forma frecuente y desarrollar proyectos interdisciplinarios que busquen conectar con problemas reales. Cabe decir que la introducción forzosa de los ámbitos en $1^{\circ}$ de la ESO en la Comunidad Valenciana ha venido acompañado por cierto revuelo en los círculos docentes, ya que a aquellos que ven en los ámbitos una oportunidad de cambio organizativo y curricular, se le suman ciertas reticencias por lo precipitado de la resolución, el ya difícil panorama del curso 2020-21 ante la crisis sanitaria y la falta de formación del profesorado para afrontar el reto con seguridad.

\section{Universidad}

La expansión de la COVID-19 ha irrumpido con fuerza en la vida, así se constata en las explicaciones y mensajes continuamente referidos a la pandemia desde el altavoz de los medios de comunicación. Unos medios, distribuidores de la información, que hacen cada vez más difícil a la ciudadanía distinguir entre el bien común y los intereses individuales y económicos, unos intereses que se camuflan en una información entre "boots", "deep fakes" y "algoritmos". Datos a la vez voluminosos e instantáneos, apuntalados por una tecnología que alimenta conversaciones cortas e inmediatas, en un tuit, sin contraste ${ }^{46}$. Así se extiende el conocimiento confuso, incompleto y plagado de incertidumbres sobre la realidad de lo que ocurre en nuestro barrio, localidad, región, estado o en el mundo.

Aparecen imágenes truncadas mezcladas con titulares y datos falsos que sin la debida aclaración pueden derivar en ciertos peligros y actitudes, como la aporofobia, la prevalencia del estatus personal sobre el colectivo, la desvalorización de la ancianidad, la regularización de la precariedad o el aumento de la vulnerabilidad social. Así que se hace muy necesario fortalecer las capacidades, los procedimientos que permitan a las personas entender lo que ocurre para que sean autónomas en sus decisiones y actuaciones ciudadanas, lo que da, si cabe, más sentido a considerar el eslogan que dice "por una educação que nos ensine a pensar e não a obedecer"

En los ámbitos de la formación básica y universitaria se han tenido que adaptar las estructuras y las metodologías de enseñanza. La educación es la encargada de dotar de argumentos y herramientas intelectuales para discernir desde el pensamiento crítico. En concreto para la formación del profesorado y la enseñanza de las ciencias sociales, concretamente de la geografía, supone un reto para llevar a cabo la acción educativa diaria con sus diferentes tareas; pero nos ha brindado una oportunidad única para constatar que la educación debe servir para afrontar los problemas de nuestro mundo ${ }^{48}$. Desde este enfoque se pueden desarrollar los saberes. Las nuevas situaciones, hechos y experiencias originados por la pandemia instaladas en la vida de las personas, sociedades y territorios, permiten trabajar de forma crítica y con un carácter integrador las diferentes dimensiones de los hechos sociales.

Para desarrollar los objetivos que competen a la enseñanza de la geografía escolar, hemos creado unas tareas a partir de los problemas de la pandemia, organizando un esquema de trabajo que responde a un orden metodológico en el cual el Geoforo, como plataforma e instrumento educativo, actúa como parte que permite desarrollar capacidades básicas y específicas del

\footnotetext{
46 Ver Campo, 2019.

${ }^{47}$ Referencia hecha por la profesora Selma Garrido Pimenta (Universidad de Sao Paulo) en su ponencia sobre formación del profesorado del I Congresso Internacional de Educação Escolar, celebrado el 24.11.2020 en Ribeirão Preto <https://youtu.be/ggqBJzCFtRM>.

${ }^{48}$ Coincidimos con lo plateado por Francisco García Pérez, 2016.
} 
alumnado en su formación como futuro docente. Esta organización de las tareas se basa en las siguientes condiciones elementales que sirven tanto para las tareas de formación del profesorado como para la Educación Primaria.

Por una parte, los problemas a tratar deben ser significativos para los estudiantes, que tengan sentido para ellos, que sepan para qué sirve y cuál es su función. Además, es preciso que haya un orden metodológico, una secuencia de actividades con una progresión en las dificultades que facilite el aprendizaje. Igualmente es aconsejable diseñar un modelo, que se pueda repetir de forma que contribuya a un trabajo sistemático con las actividades que propone, con ayudas a su desarrollo pero que consiga con el tiempo que el estudiante asuma su propio proceso y ejecución. Es decir, que potencie el trabajo autónomo del estudiante y que pueda demostrar el dominio de lo aprendido.

Las tareas propuestas, tanto para Educación Primaria como para el Grado de Primaria buscan trabajar un problema, como la pandemia por la COVID-19, desde la perspectiva práctica de una secuencia de actividades. Esta se articula en un orden metodológico que facilite un proceso de razonamiento constructivo y que arranca de la concepción que tienen los estudiantes de algún problema concreto derivado de la pandemia: una noticia en el caso de los estudiantes de Grado y la relación con su entorno más próximo en el caso de los estudiantes de Educación Primaria.

Siendo el propósito principal conocer el problema actual de la pandemia desde la observación y la indagación, el campo de observación será próximo, de forma que facilite trabajar directamente con el medio, tanto desde situaciones de clase como desde el ámbito familiar. La propuesta dirigida para $5^{\circ}$ y $6^{\circ}$ curso (10 y 11 años), como vimos en el cuadro 13 , se realiza a partir de las informaciones que se van registrando y conforman los conocimientos trabajados.

Esta tarea se presenta con un orden metodológico (cuadro 15) que facilite el trabajo para el desarrollo del pensamiento geográfico mediante una propuesta participativa de la siguiente forma:

\section{Cuadro 15. Propuesta en Educación Primaria}

- Presentación de la tarea

- Ideas previas

- Pautas de observación directa

- Cuestiones para indagar, otras preguntas además de las propuestas

- Fuentes de información: espacio hogar-clase-escuela, carteles, señalizaciones, testimonios (comunidad escolar, familias), ideas propias

- Trabajo individual y por grupos de clase

- Recogida de información en la tabla

- Puesta en común

- Trabajos de síntesis mediante murales, aplicaciones digitales, construcciones marquetería, videos informativos...

Fuente: Elaboración propia

De manera análoga, en el caso de la tarea para los estudiantes de Grado de Magisterio, tomamos la pandemia como ejemplo para desarrollar una secuencia de trabajo para abordar un problema relevante. La tarea provoca un proceso inductivo en que los estudiantes tienen que resolver unas cuestiones planteadas. Se trata de que busquen y aporten datos, hechos, conceptos y teorías que les sirvan para la construcción de su explicación referente al problema que han elegido. Una experiencia, actividad, de información y aprendizaje de manera inducida, que pretende conocer y desarrollar el pensamiento y la alfabetización geográfica mediante una estructura metodológica. Desde su inicio con el planteamiento de problema, la indagación e información 
se realiza mediante fuentes escritas, orales, datos estadísticos, cartografía o gráficas que les permitan una participación activa y ciudadana, en este caso en el Geoforo, Foro 126.

Así, en la formación del profesorado se ha diseñado la tarea (cuadro 16) contando con el manifiesto como recurso documental y el Geoforo como instrumento de contraste de información y participación con la siguiente secuencia de actividades:

\section{Cuadro 16. Propuesta para Grado Magisterio en Educación Primaria}

1. Piensa en una noticia que hable de un problema relacionado con la pandemia de la COVID 19 y que sea importante para ti.

2. Escribe 5 palabras clave que identifiquen la noticia y el problema que has elegido

3. Desarrolla el problema que has elegido según el siguiente orden de actividades:

a) Título y fuente de la noticia

c) Comparar información: establecer números relativos de contagios, muertes... índices, tasas. Seleccionar historias personales

d) Interpretar información, tanto cuantitativa como cualitativa para establecer un resumen de la situación local

e) Desarrollar generalizaciones para intuir posibles conjeturas

f) Evaluar alternativas respecto a la solución hipotética

g) Determinar los hechos para mostrar los argumentos que se defienden

h) Verificar el impacto sobre la vida de algunas personas concretas, indicando ejemplos específicos

i) Cartografiar en mapas con escala los resultados obtenidos de la presencia de la pandemia en el territorio. Acompañar si es preciso de alguna fotografía

j) Proponer un camino para desarrollar una posible solución

4. Abre el manifiesto ¿Con cuál te sientes más identificado? ¿por qué?

5. Ahora entra en el Foro 126 del Geoforo de la UNAM (Universidad Nacional de México). Observa los "Hilos" que propone el foro 126. ¿Con qué hilo relacionas el problema que has tratado? Puedes leer las participaciones que se han realizado en ese hilo o en otros para completar y contrastar tus argumentos.

6. Con la información que tienes ahora sobre el problema, elabora un resumen.

7. Comparte el resumen con tu equipo/grupo de clase $(1,2,3,4, \ldots)$ y ahora elegir uno de los temas que habéis tratado. Abordar ahora ese tema entre todos los miembros del grupo para realizar un informe sobre la cuestión de "Problemas de la pandemia: Covid 19".

8. Hacer una exposición sobre el informe del problema grupal elegido

9. Finalmente, puedes participar en el Foro 126 subiendo el resumen del problema que has elegido sobre la pandemia

Fuente: Elaboración propia

Para el estudio sobre el Foro 126 se pueden resaltar algunos análisis de las tareas elaboradas por estudiantes de Grado de Educación Primaria y que evidencian la formación del pensamiento geográfico:

1. Escala o territorio que eligen como estudio (lugar, ciudad, provincia, comunidad autónoma, estado, supranacional). Referencia a los países o tipo de población que indican en sus comentarios.

2. Referencias: autores, organizaciones gubernamentales, de carácter local, nacional, internacional, universidades, asociaciones de profesionales, prensa, medios de comunicación, ....

3. Bases de datos, estadísticas, cartografía y gráficos.

El punto 9 de la tarea (ver cuadro 16) concierne a la participación en el foro, de los 82 estudiantes de $4^{\circ}$ de Grado de Educación Primaria que han realizado la tarea, 66 han participado 
en el Foro 126 incorporando el resumen del tema que habían trabajado en relación con la pandemia. Los temas seleccionados se relacionan con problemas educativos, sociales, ambientales, económicos, sanitarios o de salud y culturales. Veamos en el cuadro 17 los temascomentarios (respuestas) que han incorporado estos estudiantes a los diferentes hilos que propone el Foro 126, así como las vistas realizadas. Algunas respuestas aparecen en el foro sin adscripción a alguno de los hilos, como la "tarea geoforo" donde se puede apreciar una tarea tipo realizada por la estudiante que la comparte.

Cuadro 17. Temas tratados en los hilos del foro 126 por los estudiantes de Grado Magisterio

\begin{tabular}{|c|c|c|c|}
\hline Hilos de foro 126 & Temas que tratan los participantes & Respuestas & Vistas \\
\hline $\begin{array}{l}\text { A: Papel } \\
\text { instituciones del } \\
\text { estado }\end{array}$ & $\begin{array}{l}\text { Residencias Mayores. Personas con TEA. Curso escolar. } \\
\text { Violencia de género. Sistema educativo español. } \\
\text { Desigualdad social. Vacuna contrarreloj. }\end{array}$ & 12 & 240 \\
\hline $\begin{array}{l}\text { B: La pandemia: } \\
\text { definiciones, } \\
\text { conceptos, } \\
\text { consecuencias }\end{array}$ & $\begin{array}{l}\text { Gestión emocional. Rastreadores. Enfermos de Alzheimer. } \\
\text { Aumento violencia de género. Salud mental. Profesorado y } \\
\text { estrés. Brecha digital. Escuelas públicas y concertadas. Ocio } \\
\text { y hostelería. Nueva normalidad. Parques infantiles. } \\
\text { Absentismo escolar. Ansiedad niños. Resultados } \\
\text { confinamiento local. Culpables del virus. Jóvenes y Ertes. } \\
\text { Crisis cultural. Expansión virus en España. Inquietud social } \\
\text { y PCR. Consecuencias educativas. Países subdesarrollados. } \\
\text { Salud de profesionales sanitarios } \\
\text { Ansiedad, depresión sociedad. TEA. Regreso a la escuela. } \\
\text { Deporte y Covid }\end{array}$ & 28 & 427 \\
\hline $\begin{array}{l}\text { C: Iberoamérica } \\
\text { ante la pandemia: } \\
\text { respuestas de } \\
\text { territorios }\end{array}$ & $\begin{array}{l}\text { Escuela. Ética médica. Segunda ola en C. Valenciana. } \\
\text { Mascarillas. Desigualdades en Madrid. Índices de } \\
\text { mortalidad. Actuaciones de los dirigentes. }\end{array}$ & 7 & 210 \\
\hline $\begin{array}{l}\text { D: Retos para la } \\
\text { docencia } \quad y \\
\text { aprendizaje en } \\
\text { ciencias sociales }\end{array}$ & $\begin{array}{l}\text { Ventilación en las aulas. Cambio climático. Educación } \\
\text { emocional. Negacionismo } \\
\text { Brecha educativa. Sociedades musicales }\end{array}$ & 6 & 235 \\
\hline $\begin{array}{l}\text { E: Salud pública y } \\
\text { privatización de la } \\
\text { sanidad }\end{array}$ & Medidas anticovid & 1 & 124 \\
\hline $\begin{array}{l}\text { F: Estrategias } \\
\text { enseñanza frente } \\
\text { la Covid }\end{array}$ & $\begin{array}{l}\text { Reapertura escolar. Brecha digital. Infancia. Educación } \\
\text { emocional. Responsabilidad social }\end{array}$ & 5 & 202 \\
\hline \multirow{7}{*}{$\begin{array}{l}\text { Otros } \\
\text { adscripción }\end{array}$} & OMS datos alarmantes & \multirow{7}{*}{7} & \\
\hline & Brecha digital de la COVID-19 & & 235 \\
\hline & Prueba en menores de una vacuna china & & 40 \\
\hline & La segunda ola en España & & 39 \\
\hline & Coronavirus en la C. Valenciana & & 52 \\
\hline & Confinamiento a nivel local por descontrol del virus & & 43 \\
\hline & Tarea Geoforo & & 62 \\
\hline
\end{tabular}

Fuente: Elaboración propia 
Veamos cómo se puede trabajar el tema de "La brecha digital y la Covid19". Las actividades propuestas (cuadro 16) posibilitan técnicas de análisis que facilitan la alfabetización geográfica y la redacción de un comentario argumentado para el Foro 126. A continuación, alguna respuesta de estas actividades de la tarea que ha realizado una estudiante ${ }^{49}$ :

- Piensa en una noticia que hable de un problema relacionado con la pandemia de la COVID-19 y que sea importante para ti.

La COVID-19 ha aumentado la brecha digital entre quienes tienen acceso a dispositivos tecnológicos, a una Internet fiable y a los conocimientos necesarios para navegar en línea y quienes no lo tienen. El problema me ha afectado personalmente, ya que estaba enseñando en una escuela internacional cuando comenzó la pandemia. En tres días tuve que cambiar todas las lecciones a un aula virtual.

- Comparar información: establecer números relativos de contagios, muertes... índices, tasas. Seleccionar historias personales

Datos cuantitativos:

oDesde lo local hasta lo global, casi el $50 \%$ de los estudiantes matriculados en todo el mundo no pueden asistir a la escuela o lo hacen parcialmente (UNESCO, 2020, datos del 24 de septiembre). Ver figura 10.

○Ministerio de Educación: El 10\% de los 8,2 millones de escolares españoles no pueden seguir las clases en línea, algunas estimaciones se acercan al $20 \%$.

Figura 10. Impacto de la COVID-19 en la supresión de actividad escolar

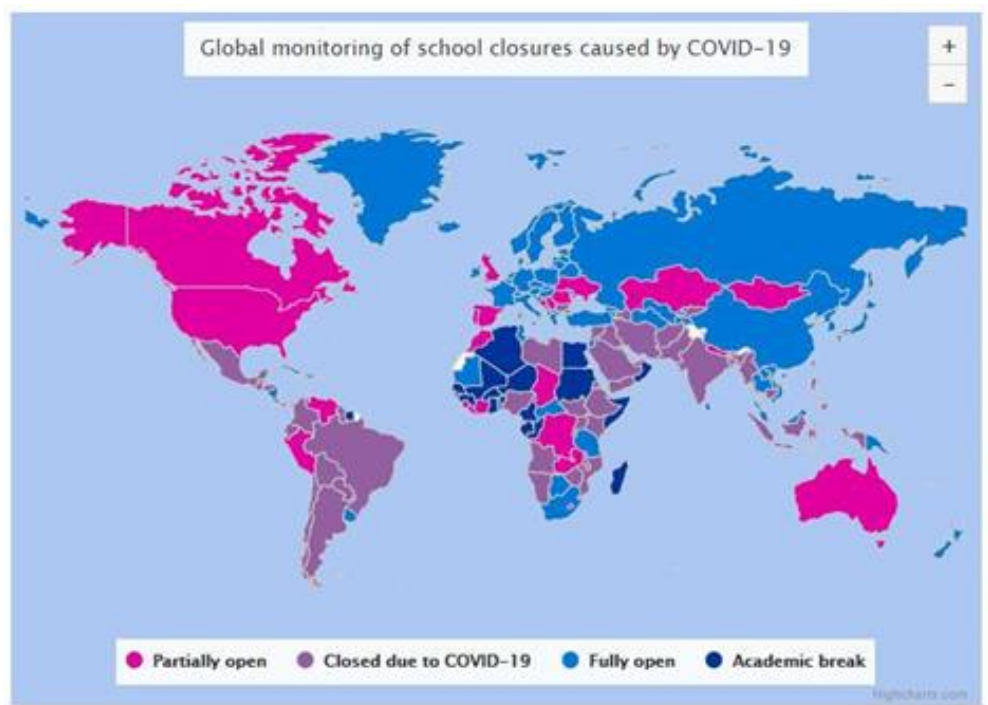

Visualize evolution over time.

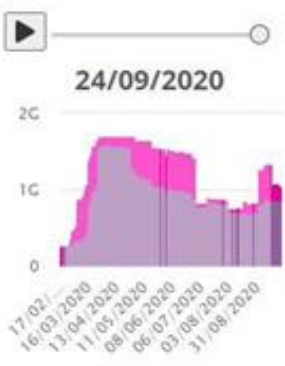

$850,506,853$ affected

learners

$48.6 \%$ of total enrolled

learners

52 country-wide closures

Fuente: Datos de UNESCO ${ }^{50}$

Datos cualitativos:

oEntrevista informal con un profesor que trabaja en Caxton College - dificultad para hacer frente a la enseñanza mixta, sobre todo para los alumnos que están en línea. También destacó un cambio en el liderazgo, que pasó de ser democrático a ser más autocrático.

\footnotetext{
${ }^{49}$ Las actividades mostradas corresponden a la alumna Marie Meyer, estudiante de Erasmus que acude a las clases de la asignatura de Didáctica de las Ciencias Sociales Aspectos Aplicados de $4^{\circ}$ Grado de Educación Primaria en la Facultat de Magisteri de la Universitat de València. La alumna ha accedido a comunicar su nombre en esta comunicación.

${ }^{50} \mathrm{Ver}<$ https://data.humdata.org/dataset/global-school-closures-covid19>.
} 
- Interpretar información, tanto cuantitativa como cualitativa para establecer un resumen de la situación local

......Mientras que los profesores pueden preocuparse por alcanzar los objetivos académicos, los padres pueden tener más dificultades por el efecto socioemocional de quedarse en casa......

- Verificar el impacto sobre la vida de algunas personas concretas, indicando ejemplos específicos

No tengo ejemplos concretos de la situación local en Valencia, sino la experiencia de personas que conozco en todo el mundo.

D.M., por ejemplo, es un estudiante de 15 años de la escuela Shaw Park Combined en Sudáfrica que estuvo sin educación escolar durante más de 5 meses. Vive en una zona rural sin acceso a Internet y tiene que viajar largas distancias para recibir la red en su teléfono.

El resultado de este proceso le ha permitido a esta alumna realizar un resumen a modo de síntesis:

\section{Resumen:}

Cuando comenzó la pandemia, me encontré en el puesto de una profesora de una escuela internacional que tenía que completar su pasantía en línea. De un día para otro se me exigió ser digitalmente competente. Mientras reforzaba rápidamente mis propias habilidades, también tenía que preparar un aula llena de estudiantes para su aprendizaje en un entorno digital. Algunos de ellos habían salido del país y se habían incorporado desde diferentes zonas horarias, otros compartían dispositivos con toda su familia y estudiantes con necesidades educativas especiales que simplemente se sentían abrumados por los rápidos cambios. Y estos desafíos surgieron en un entorno privilegiado: ¿cómo podrían los contextos desfavorecidos gestionar el aprendizaje digital? En España se estima que un 10\% de 8,2 millones de estudiantes no pueden continuar su educación en línea, lo que afecta específicamente a las zonas locales con acceso limitado a Internet. Pero la solución puede estar no sólo en el despliegue de recursos sino en la adquisición de habilidades que lleven a la alfabetización digital. Los estudiantes que no pueden recibir el apoyo de sus padres requieren aptitudes para acceder a los materiales y poder evaluar críticamente la riqueza de la información disponible en línea. Para ello es necesario un plan de inclusión a largo plazo que permita salvar la brecha digital, que actualmente es el statu quo y que podría amenazar la igualdad de oportunidades para todos los estudiantes.

Igualmente, en el Máster de Profesor/a de Educación Secundaria el alumnado ha desarrollado la competencia comunicativa, a través del estudio de las noticias de la pandemia. Con un esquema de trabajo semejante, han analizado los factores y consecuencias de la pandemia. Así, un total de 40 personas han estudiado algunos problemas relevantes como la desigualdad social en la incidencia del virus; las relaciones entre el espacio subjetivo de ocio y la crisis del sector empresarial, la incidencia en el medio local de la localidad vivida o la pandemia y la salud mental

Estas tareas han sido trabajadas en el Foro 26 y sus comentarios han coincidido con el alumnado del Grado de Valencia y del Grado de la Universidad de Castilla-La Mancha, lo que ha facilitado la presencia de algunos intercambios de opiniones, que han permitido valorar las coincidencias. Un objetivo que se debe ampliar en años posteriores. 


\section{Evaluación de los objetivos del Geoforo}

El Geoforo de Educación, Geografía y Sociedad ha nacido hace más de diez años para facilitar el intercambio global de argumentos sobre los problemas sociales desde las instituciones escolares y académicas. Para ello era preciso consolidar grupos locales que pudieran pensar, con una actitud de praxis escolar, en sus preocupaciones cotidianas como profesores y miembros de una comunidad social educativa. Esta era, y es, la finalidad básica del Geoforo. Una plataforma que alberga debates académicos para avanzar en la praxis didáctica con la ayuda de los grupos de innovación y de las diferentes secciones del proyecto internacional Nos Propomos!, que como sabemos mantiene un ritmo de trabajo creciente en centros de Educación Primaria y Secundaria, fomentando la participación ciudadana del alumnado.

Las reuniones celebradas en el Coloquio, en el mes marzo de 2019 en Bogotá, nos ha permitido verificar los avances logrados y las posibilidades de mejorar. Para ello con revistas de grupos locales que nos facilitan la labor de difusión de los resultados de las investigaciones realizadas, así como otras de carácter más general. Son los casos de Biblio $3 W^{51}$ y Aracne ${ }^{52}$ en la plataforma Geocrítica de la Universitat de Barcelona, Anekúmene de la Universidad Pedagógica Nacional de Bogotá y grupo Geopaideia ${ }^{53}$, de la revista Didáctica de las ciencias experimentales y sociales de la Universitat de València ${ }^{54}$ o la revista Investigación en la escuela ${ }^{55}$, relacionada con el grupo IRES.

Una vez que se ha alcanzado el primer objetivo de consolidar las redes sociales de grupos de innovación y la posibilidad de difundir los resultados de argumentos sobre la praxis escolar, hemos avanzado en definir algunas propuestas de investigación. En este sentido se ha avanzado en la definición de categorías conceptuales para poder transformar las opiniones y casos anecdóticos en planteamientos de conjeturas sobre problemas del mundo escolar ${ }^{56}$. La apertura del nuevo foro en la UNAM de México ${ }^{57}$ nos permitirá disponer de un lugar virtual donde debatir sobre qué categorías determinan un debate. Un ejemplo evidente de lo que señalamos son las intervenciones de Valencia en el análisis de comentarios anteriores en el Foro $26^{58}$, que posteriormente se complementa con la propuesta de clasificación de categoría conceptual en el Foro 126. Y, más relevante todavía, la posibilidad de realizar análisis conjuntos desde tres países diferentes, como es el caso del estudio realizado por la profesora brasileña Silvia Sousa, la profesora colombiana Nancy Palacios y el español Diego García sobre la incidencia de la COVID-19 y su repercusión en el mundo escolar ${ }^{59}$.

Por otra parte, las alianzas personales y de grupos que se están tejiendo han dado lugar a resultados positivos. Un ejemplo ha sido el encuentro celebrado el 31 de octubre de 2020 con

\footnotetext{
$51<$ https://revistes.ub.edu/index.php/b3w/index $>$.

$52<$ https://revistes.ub.edu/index.php/aracne/index $>$.

$53<$ http://www.anekumene.com/index.php/revista $>$.

$54<$ https://ojs.uv.es/index.php/dces>.

$55<$ https://editorial.us.es/es/revistas/investigacion-en-la-escuela>.

${ }^{56}$ Un ejemplo es el trabajo de Fita y Barbosa (2020)

$<$ https://revistas.pedagogica.edu.co/index.php/anekumene/article/view/12462〉.

57 <http://www.geoforo.unam.mx/secforo/index.php>.

${ }^{58}$ Ver los comentarios registrados en enero de 2021 por Adrià Lapuente y María Cascales: <http://geoforoforo2.blogspot.com/2020/03/foro-26-el-coronavirus-una-experiencia.html\#comment-form>.

${ }^{59}$ Sousa, Palacios y García, 2020 <http://dx.doi.org/10.35786/1645-1384.v20.n3.13> que ha tenido repercusión en las noticias de la Universitat de València: <http://socialsuv.org/2021/02/02/articulo-revista-curriculo-semfronteiras/>.
} 
más de treinta miembros del Geoforo para debatir los problemas de la pandemia en cada país; en especial, hemos valorado la situación del sistema escolar. Ese mismo día se reunían los jóvenes investigadores de Nós Propomos!, que están fraguando redes de complicidad para avanzar en el análisis y explicación de los problemas sociales ${ }^{60}$. Desde el Geoforo se estimula la organización de redes de innovación e investigación, pero para su ejecución es precisa la colaboración de personas desde la escala local, como es el caso de la profesora Silvia Sousa Fernandes desde Marilia ${ }^{61}$.

Como venimos sintetizando en este artículo, para que podamos actuar de forma global es necesario pensar y actuar en la escala global y local. En este aspecto, un ejemplo paradigmático es el proyecto Nós Propomos!, coordinado por el profesor de la Universidade de Lisboa Sérgio Claudino $^{62}$. Las actividades generaron un entusiasmo participativo en el alumnado de los niveles no universitarios (de Primaria hasta Secundaria no obligatoria), que repercute en la gestión local de los problemas sociales ${ }^{63}$. Localmente se han construido convenios de colaboración entre universidades, escuelas y municipios y, a veces, asociaciones locales. Emerge el objetivo de una escuela, así como una educación geográfica y ciudadana directamente vinculada a los desafíos comunitarios. El proyecto, surgido en Portugal (2011/12), es implementado también en España, Brasil, Perú, Colombia, México, y también en Mozambique. Es una red iberoamericana directamente apoyada por el Geoforo, como es en el caso del Foro 24, y que se pretende expandir a otros países, a pesar de la pandemia.

Los ejemplos referidos nos animan a continuar en la labor de pensar y actuar globalmente. Pero para ello, las redes virtuales deben constituirse en redes de personas, ideas y proyectos materiales. Ese el objetivo que perseguimos desde 2008 y en el que continuamos doce años después.

\section{Referencias bibliográficas}

CAMPO, Benito. Alfabetización geográfica, ciudadanía y educación geográfica en la formación del profesorado: elaborar tareas conectadas con el Geoforo. In Liliana Rodríguez, Nancy Palacios, Xosé M. Souto (Eds), La construcción global de una enseñanza de los problemas sociales desde el geoforo iberoamericano. Valencia: Nau llibres, 2019, p. 302-319 <https://observatoriogeohistoria.net.br/wp-content/uploads/2019/11/LIVRO-geoforoiberoamericano-2019.pdf>.

CLAUDINO, Sérgio. Project We Propose! Building Territorial Citizenship from School. In José A. Pineda-Alfonso, Nicolás de Alba-Fernandez, Elisa Navarro-Medina, Handbook of

\footnotetext{
${ }^{60}$ Este grupo se ha vuelto a reunir de manera virtual el día 21 de noviembre de 2020, consolidando una red de jóvenes investigadores en Brasil, Colombia, México y España. El resumen de la actividad realizada el día 31 de octubre se puede consultar en <http://geoforonoticias.blogspot.com/2020/11/resumen-de-la-actividad-deformacion-de.html> y <http://geoforodocumentos.blogspot.com/2020/11/reunion-del-geoforo-del-dia-31de.html>.

${ }^{61}$ XX Fórum de Análise de Conjuntura - UNESP/Marília-SP 24 a 28 de agosto de 2020:

<http://geoforonoticias.blogspot.com/2020/09/xx-forum-de-analise-de-conjuntura.html>.

${ }^{62} \mathrm{Se}$ pueden consultar las referencias de los trabajos publicados por S. Claudino et al. (2019).

${ }^{63}$ Como ejemplo, podemos citar las sesiones O Projeto Nós Propomos! e a Cidadania em Tempo de Pandemia, promovido pela Universidade Federal do Piauí e pela Instituto de Geografia e Ordenamento do Território da Universidade de Lisboa e que decorreu nos dias 16 e 23 de maio. Projeto Nós Propomos!/Proyecto Nosotros Proponemos! Falam os estudantes! Los estudiantes hablan!, promovido pela Universidade Federal do Piauí e pela Instituto de Geografia e Ordenamento do Território da Universidade de Lisboa e que decorreu no dia 2 de setembro.
} 
Research on Education for Participative Citizenship and Global Prosperity. Hershey: IGI Global, 2019, p. 350-382.

CLAUDINO, Sérgio; SOUTO, Xosé M.; RODRIGUEZ DOMENECH, Ma Angeles; BAZOLLI, João; LENILDE, Raimundo; LUCIMAR GENGAGNEL, Claudionei; MENDES, Luís; TADEU SILVA, Adilson (Ed.) Geografia, Educação e Cidadania. Lisboa: Centro de Estudos Geográficos, 2019, 910 páginas.

FITA, Sara; BARBOSA, Yeimy. Experiencias desde el Geoforo Iberoamericano: prácticas docentes en la enseñanza y el aprendizaje de la geografía en la escuela y la universidad. $\begin{array}{lllll}\text { Anekumene, número } & 16, & 2020, & \text { p. } & 60-68\end{array}$ <https://revistas.pedagogica.edu.co/index.php/anekumene/article/view/12462>.

FITA, Sara; CLAUDINO, Sergio. SOUTO, Xose. La globalización del Geoforo Iberoamericano en 2018. Biblio3W, Revista Bibliográfica de Geografía y Ciencias Sociales, XXIII núm. 1.258, 2018 <http://www.ub.es/geocrit/b3w-1258.htm>.

GABALDÓN, D., OBIOL, S. Guía sobre tiempos escolares. València: Generalitat Valenciana; Valencia: Confederació d'AMPAS Gonzalo Anaya, 2016 $<$ https://doi.org/10.7203/CREATIVITY.1.12062>.

GARCÍA MONTEAGUDO, Diego. La representación social del medio rural. Un análisis desde la geografía escolar, Universidad de Valencia. Tesis doctoral. 2019 <http://socialsuv.org/2019/12/04/tesis-doctoral-de-diego-garcia-monteagudo/>.

GARCÍA PÉREZ, Francisco. Educar en la escuela para afrontar los problemas del mundo. En VV.AA. Más allá de lo imposible. La dimensión política de los derechos humanos en el siglo XXI. Tafalla: Ed. Txalaparta, 2016, p. 145-171.

RODRÍGUEZ PIZZINATO, Liliana Angélica; PALACIOS MENA, Nancy; SOUTO GONZÁLEZ, Xosé Manuel (editores). La construcción global de una enseñanza de los problemas sociales desde el Geoforo Iberoamericano, Barcelona: Geocrítica Textos Electrónicos, 2019 <http://www.ub.edu/geocrit/geoforo_iberoamericano_2019.pdf>.

RODRÍGUEZ PIZZINATO, Liliana Angélica; PALACIOS MENA, Nancy; SOUTO GONZÁLEZ, Xosé Manuel (Editores). La construcción global de una enseñanza de los problemas sociales desde el Geoforo Iberoamericano, Valencia: Nau Llibres y Universidad de Barcelona-Geocrítica, 2020.

SOUSA, Silvia; GARCÍA, Diego; SOUTO, Xose. Educación Geográfica y las salidas de campo como estrategia didáctica: un estudio comparativo desde el Geoforo Iberoamericano, Biblio3W. Revista Bibliográfica de Geografía y Ciencias Sociales, núm 1.155, 2016 $<$ http://www.ub.es/geocrit/b3w-1155.pdf>.

SOUSA, Silvia; GARCÍA-MONTEAGUDO, Diego; PALACIOS, Nancy. Covid-19 y el cierre de escuelas: aportes de las ciencias sociales para la construcción de un currículo postcrítico desde el Geoforo Iberoamericano. Revista Currículo sem Fronteiras. 20 (3), 2020, p. 842-870. <http://dx.doi.org/10.35786/1645-1384.v20.n3.13>. 
SOUTO, Xose; CLAUDINO, Sergio; GARCÍA, Francisco. Diversidades geográficas y construcción de un saber crítico para participar en red. La experiencia del Geoforo Iberoamericano. Balance inicial. Biblio 3W. Revista Bibliográfica de Geografía y Ciencias Sociales, XV núm. 902, $2010<\mathrm{http}: / / w w w . u b . e s / g e o c r i t / b 3 w-902 . h t m>$.

SOUTO, X. y DURÁN, D. La consolidación de un proyecto iberoamericano de educación. La experiencia del Geoforo. Balance anual de 2011. Biblio 3W. Revista Bibliográfica de Geografía y Ciencias Sociales. Barcelona: Universidad de Barcelona, núm. 955, 2011 <http://www.ub.edu/geocrit/b3w-955.htm>.

SOUTO GONZÁlEZ, Xosé Manuel; PALACIOS MENA, Nancy; RODRIGUEZ PIZZINATO, Liliana Angélica. Un congreso para imitar. Cuando el compromiso y la coherencia convergen. Biblio3W, Revista Bibliográfica de Geografía y Ciencias Sociales. Barcelona: Universidad de Barcelona, vol. XXIV, $\mathrm{n}^{\circ} \quad 1.279, \quad 2019$ <https://revistes.ub.edu/index.php/b3w/article/view/28493>.

SOUTO, Xosé M.; CLAUDINO, Sérgio. Construímos uma Educação Geográfica para a Cidadania Participativa. O caso do Projeto Nós Propomos! Revista Signos Geográficos Boletim NEPEG de Ensino de Geografia, Vol. 1, 2019, p. 1-16 <https://www.revistas.ufg.br/signos/article/view/59171>.

Ficha bibliográfica:

CAMPO PAÍS, Benito; FITA ESTEVE, Sara; MARTÍNEZ CAMARENA, María; SOUTO GONZÁLEZ, Xosé Manuel. La pandemia y el Geoforo lberoamericano en 2020. Ar@cne. Revista Electrónica de Recursos de Internet sobre Geografia y Ciencias Sociales. Barcelona: Universidad de Barcelona, I de abril de 202I, vol. XXV, $n^{\circ}$ 253. DOI: https://doi.org/I0.1344/ara2021.253.34376

\section{Menú Geo Crítica}

